\title{
A autoapresentação dos portugueses na plataforma de online dating Tinder
}

\section{The self-presentation of the Portuguese on Tinder's online dating network}

\author{
Jorge Vieira*, Rita Sepúlveda** \\ * Professor Auxiliar Convidado, ISCTE-IUL; Investigador Associado CIES - Centro de Investigação e Estudos de Sociologia \\ ** Estudante de doutoramento em Ciências da Comunicação, ISCTE-IUL; CIES - Centro de Investigação e Estudos de Sociologia
}

Resumo

\begin{abstract}
As plataformas de online dating são uma realidade cada vez mais presente, no entanto é escassa a investigação relativa aos utilizadores portugueses. Desta forma a investigação desenvolvida no presente artigo teve como objetivo principal explorar as estratégias de autoapresentação mediada dos utilizadores portugueses e do processo de construção de perfis individuais na rede de online dating Tinder.

O desenho da pesquisa mobilizou procedimentos de recolha de dados assente numa metodologia mista, combinando metodologias qualitativas e quantitativas, através da articulação da recolha de dados via observação não participante de 200 perfis (resultando num corpus de 701 fotografias e 87 textos), entrevista (10) e consequente análise de conteúdo.

Como principais resultados e através da triangulação da análise dos resultados obtidos, foi possível observar singularidades, mas também padrões, nas práticas de autoapresentação e desempenho identitário, tanto em termos de imagens, como na informação textual.

As diferentes estratégias envolvidas na autoapresentação demonstraram a reflexividade acionados pelos sujeitos num jogo dialético de expectativas recíprocas e leitura dos contextos mediados colapsados e audiências imaginadas. Encontraram-se fortes regularidades sociais, que demonstraram o carácter situacional da apresentação do eu que adapta as lógicas de ação a diferentes contextos. Foi assim evidenciada a "ordem da interação" (Goffman, 1983) num contexto mediado de autoapresentação pública cada vez mais colapsado em rede e em que as fronteiras com o privado (bastidores) são cada vez mais ténues.
\end{abstract}

Palavras-chave: online dating; autoapresentação; Tinder; relacionamentos online; gestão impressões; mediação

Abstract

Online dating platforms are a present reality, however, investigation regarding the Portuguese users is scarce. Therefore, the investigation conducted in the present article has the exploration of the strategies of mediated self-presentation from the Portuguese users and the process of building individual profiles on the online dating platform Tinder as a main goal.

The outline of this research focuses on a mixed methodology for data collection, combining qualitative and quantitative methods, where data is collected via non-participant observations of 200 profiles (resulting in a corpus of 701 photographs and 87 texts), interviews (10), and subsequent content analysis.

As main results obtained through data analysis triangulation, it was not only possible to observe singularities but also patterns in the self-presentation practices and identity performance, both in terms of images and textual information.

The different strategies involved in the self-presentation demonstrated the reflexivity triggered by the subjects, in a dialect game, with mutual expectations and reading of the mediated collapsed contexts and imaginary audiences. Strong social regularities were found, which demonstrate the situational character of the self-presentation, which shapes the logics of action. The "interaction order" (Goffman, 1983), in a mediated context of public self-presentation, increasingly more collapsed in a web, and where the barriers with the private (backstage) appear to be more blurred, was evidenced.

Keywords: online dating; self-presentation; Tinder; online relationships; impression management; mediation

Copyright (c) 2017 (Jorge Vieira and Rita Sepúlveda). Licensed under the Creative Commons Attribution-NonCommercial Generic (cc by-nc). Available at http://obs.obercom.pt. 


\section{Introdução}

Num momento histórico em que os media são, cada vez mais, a textura da experiência (Silverstone, 1999: 2), todas as dimensões da vida em sociedade são marcadas pela mediação (Silverstone, 2005; Lievrouw e Livingstone, 2006; Couldry, 2012) e, em particular, pela mediação online, sobretudo pela internet (Finkel, 2012: 4).

Neste contexto, os estudos sobre a apresentação do self em contextos online, mais precisamente em redes sociais online em relação com temáticas interligadas como: a identidade pessoal, comunicação interpessoal mediada, sociabilidades e relações online - das mais interpessoais mais alargadas (Baym, 2011) às mais íntimas (Jamieson, 2013) e diádicas que remetem para contextos de online dating (Gunter, 2008; Chambers, 2013) são um campo emergente e com crescente interesse académico interdisciplinar (sociologia, psicologia, ciências da comunicação). Estas investigações detêm não só um património teórico consolidado, inspirado numa matriz dramatúrgica e do interacionismo simbólico, mas também um acervo empírico acumulado relativamente considerável (Bargh, 2002; Hardey, 2002; Ellison, 2006; Walther, 2007 Whitty, 2008; Guadagno, 2012; Rui, 2013; Chiang, 2015; Lee-Won, 2014; Baumgartner, 2015; Bareket-Bojmel, 2016; Wotipka, 2016).

Contudo estes tipos de pesquisas rapidamente se tornam desatualizados - idiossincrasia de uma área de estudo intimamente ligada ao avanço tecnológico e seus usos sociais, colocando assim um desafio acrescido ao acompanhar dessa dupla volatilidade (Wajcman, 2002; Livingstone, 2004). Com efeito, uma leitura diacrónica da evolução histórica da popularidade de várias redes de online dating demonstra que estas têm sido alvo de sucessivos ciclos de adesão e abandono e como tal apropriadas e domesticadas (Haddon, 2004; Bakardjieva, 2005; Becker el al., 2006), de forma diferenciada e com volumes de adesão distintos.

Desde a emergência destes serviços baseados na internet que se nota um aumento no volume de indivíduos que utilizam as TIC para relações mediadas (Anderson, 2006: 153), assim como a procura e oferta dos mesmos. Tal facto pode dever-se a alterações em como os indivíduos se estão a relacionar com os outros, consequência, entre outras, das alterações na vida pessoal e profissional, a uma crescente presença da comunicação em rede, da forma como adotam as tecnologias nas suas vidas e consequentemente de como este tipo de plataformas se imiscuíram na sociedade e como se passam a classificá-las socialmente (DeMassi, 2006).

A crescente visibilidade mediática e número de utilizadores de redes de online dating (Madden e Lenhart 2006; Lenhart, 2009), ajudam a sustentar empiricamente uma tendência não só para a familiarização com este tipo de serviços no imaginário coletivo, mas também, do ponto de vista das práticas, um acréscimo dos utilizadores registados neste tipo de serviços, denotando-se ainda uma evolução para o formato móvel (Smith, 2016).

Resgatada a pertinência da temática deste artigo, importa olhar para o contributo especial deste estudo atual e centrado na apresentação do eu numa plataforma de relacionamento e encontros, quando comparado com alguns estudos disponíveis e que incidem sobre a realidade portuguesa.

Note-se desde já que o foco do mesmo não incidiu na tecnologia e no meio em si, mas sim, numa ótica da sociologia da mediação (Silverstone, 2005; Lievrouw e Livingstone, 2006) nos processos de mediação (Couldry, 2012) e de apresentação do eu mediada. A questão de partida foi a seguinte: como é que os utilizadores portugueses das plataformas de online dating móveis se apresentam nas mesmas? O objetivo do artigo passou pela análise das estratégias de apresentação do eu online em contextos mediados de online dating respondendo a questões subsidiárias tais como qual a importância atribuída ao conteúdo visual e conteúdo escrito? Que tipo de informações são mais partilhadas? O que é que os utilizadores pretendem revelar sobre si através das 
imagens partilhadas? Serão registadas diferenças na estratégia de autoapresentação visual e/ou escrita em função do género?

Do ponto de vista da representatividade, o estudo foi conduzido com uma amostra composta por 200 perfis, 100 do género masculino e 100 do género feminino, resultando num corpus de 701 fotografias e 87 textos, fazendo uso de um desenho da pesquisa alicerçado numa metodologia mista (Bryman, 2012) com ênfase na análise visual e de conteúdo, mas também articulada com entrevistas e sendo delimitada temporalmente entre Maio e Novembro de 2016 e aos utilizadores portugueses da plataforma de online dating Tinder.

\section{Revisão da Literatura}

Mediação, internet, redes sociais e o mobile online dating

Num processo de transformação tecnológica e social relativamente recente denota-se o incremento de importância das chamadas redes sociais online ou dos chamados social media (Hinton e Hjorth, 2013; Fuchs, 2014). Estamos assim num momento histórico em que alguns caracterizam como sendo de individualismo em rede (Rainie e Wellman, 2012), e onde os novos media e plataformas em rede permitem o acesso a novas redes sociais pelos efeitos de conectividade e latent ties (Haythornthwaite, 2002) ou weak ties (Granovetter, 1973, 1983) podendo fomentar o aumento do capital social (Neves, 2013).

Através desta rede global, o utilizador pode exponenciar as possibilidades de contacto já que, em teoria, esta será mais extensa do que a sua rede pessoal offline. Outorgando assim a oportunidade de contacto com aqueles que estão ligados à mesma rede, independentemente do local onde se encontram, e com um conjunto de utilizadores que são sugeridos em função dos perfis e pela ação do algoritmo. Neste sentido, o papel da internet foi fundamental no desenvolvimento e no sucesso deste tipo de plataformas e das redes sociais online, na medida em que esta tem sido um meio através do qual é facilitada a comunicação entre utilizadores a partir de um conjunto composto por várias modalidades (Dutton, 2013: 1).

Neste panorama de uma crescente tendência para uma internet relacional (Lievrouw, 2012), a propensão de comunicação mediada entre pessoas pode ser fomentada em várias áreas mais especializadas, seja em redes sociais nas quais se privilegiam as relações laborais (exemplo Linkedin), seja em comunidades com um interesse comum como por exemplo a procura e oferta de apartamentos para alugar (exemplo Airbnb), ou quer esta ocorra em redes sociais para encontrar amigos ou fazer novas amizades (exemplo Facebook).

Atualmente até no domínio das relações interpessoais (Solomon, \& Theiss, 2012) se adiciona agora uma camada comunicacional ao face a face: o online (Baym, 2011). Como tal, até relações mais íntimas podem remeter para contextos de online dating (Lawson, 2006; Gunter, 2008; boyd, 2010; Gershon, 2010; Pascoe, 2010; Chambers, 2013; Jamieson, 2013) e que, por sua vez, podem operar sobre uma lógica em rede de intimidade mediada (Chambers, 2013) e até de afetividade móvel (Hjorth e Lim, 2012).

Assim sendo, com o aparecimento da internet e devido às suas características, a comunicação e o relacionamento entre os indivíduos tem sofrido reconfigurações, estando esta presente em muitas das ações diárias e no resultado das mesmas (Baptista, 2015: 152) através de novas e múltiplas soluções comunicacionais e contextos específicos - de conversas sincrónicas a publicações e comentários (Sevcikova, 2011: 2).

No entanto, apesar da relação histórica entre artefactos de mediação e relações humanas as tecnologias de comunicação e informação têm vindo a evoluir, como resultado da adoção e domesticação (Haddon, 2004; 
Bakardjieva, 2005; Berker el al.., 2006), e, consequentemente de forma dialética, a maneira como se comunica tem também ela sofrido alterações pela introdução de novas dinâmicas em rede.

Têm vindo a proliferar redes sociais que pretendem promover o encontro de parceiro(s) amoroso(s)/sexual(ais) (Casimiro, 2014: 121): as plataformas de online dating. Este tipo de plataformas começa a deter alguma expressão (Madden and Lenhart, 2006; Lenhart, 2009; Dutton el al.., 2009; Gunter, 2008) e têm-se consolidado junto dos utilizadores com uma base já considerável e imiscuindo-se nas rotinas quotidianas de muitos. No entanto, apesar da aparente novidade, os serviços de matchmaking e o recurso às tecnologias de informação como ferramenta auxiliar para o encontro de um parceiro não são algo exclusivo dos tempos atuais (Ellison, 2006: 416). Nem a relação entre, por um lado, comunicação mediada e, por outro, relações interpessoais não é nova (Fischer, 1993; Marvin, 1988; Standage, 2007) - basta ver o impacto da introdução do telefone na vida doméstica e privada. A estes fatores alia-se o facto de que com o aparecimento da internet de banda larga móvel e de novos ou alterados aparelhos tecnológicos portáteis, seja possibilitada a dilatação do raio de ação e de temporalidades do online dating. A procura de parceiros e a comunicação síncrona através de sites passa também a ser móvel, fazendo com que a possibilidade de comunicação com outros utilizadores e consequentemente de encontro seja, potencialmente, mais imediata. Existem inclusive aplicações (Blackwell, 2014), como a que serve de meio para este estudo, cuja lógica de funcionamento assenta também na geolocalização, sendo esse um dos critérios a definir aquando da procura de um possível parceiro. Esta característica parece ser um fator importante para os utilizadores de aplicações de online dating na medida em que o reconhecimento da importância do local parece ter atraído o interesse destes para as mesmas (Licoppe, 2015: 2). No entanto é necessário ter em conta que "o design de sites de redes sociais, incluindo o software das aplicações ou ferramentas de envolvimento para fazer ligações pessoais, desempenha um papel chave em moldar as comunicações dos utilizadores" (Chambers, 2013: 5) sendo importante referir a este ponto o Tinder e as suas affordances (Hutchby, 2001; Selwyn, 2012).

É assim possível afirmar que se está perante uma adaptação do negócio, já que estes serviços para além de se terem vindo a desenvolver em meios diferentes dos anteriores também estão assentes em tecnologias com distintas características e potencialidades, adequando-se às transformações do quotidiano dos utilizadores. Para além da imediatez, também é possível definir à partida um conjunto de características reportadas que interessam num possível parceiro eliminando assim todos os restantes - tornando a procura mais eficaz.

Importa, porém, distinguir estas plataformas das demais já que o "online dating refere-se mais especificamente a uma variedade de atividades iniciais de relacionamento, incluindo a seleção de um potencial parceiro e ter o primeiro contacto com ele antes da relação migrar para offline' (Sprecher, 2009: 762). Ainda assim, e de forma generalista os princípios de funcionamento das plataformas de online dating são idênticos aos de outras redes sociais, após o registo e criação de um perfil, o propósito é fazer com que os utilizadores se liguem e comuniquem entre si de forma expedita e em rede sendo que esta ligação poderá acontecer através de elos em comum, indivíduos ou interesses. As plataformas de online dating baseiam-se em conseguir sugerir aos utilizadores um conjunto de possíveis parceiros que, tendo em conta determinadas características, gostos ou interesses, sejam a sua correspondência (Hall, 2010; Zytko, 2014). Desta forma, poder-se-á afirmar que estas plataformas podem ser compreendidas como um sistema através do qual os utilizadores registados podem estabelecer ligações e comunicar de forma mediada entre si, através de dispositivos ligados à internet com o objetivo de estabelecerem um relacionamento potencialmente amoroso e/ou sexual.

É fundamental recordar que o processo se desenvolve através de um dispositivo tecnológico, ou seja, a comunicação é mediada, constituindo esta característica um fator diferenciador na ausência da comunicação 
presencial cara-a-cara (Kang, 2011: 205). Neste sentido, e parte da sua especificidade, os aspetos que os utilizadores revelam sobre si nas plataformas de online dating podem ser determinantes na construção de um juízo de valor sobre estes e podem consequentemente levar ou não ao contacto por parte de outrem. A forma como os utilizadores se apresentam, seja no formato escrito ou através de fotografias, pode ser decisiva para o início de um contacto, estabelecimento de uma comunicação e posteriormente, através da troca de mensagens ou não, avaliação do transitar da relação do online para o offline. Sendo que, esta construção do perfil, ou seja, do eu online dos utilizadores, poderá ter impacto nos resultados, como se comprova nos estudos realizados por Mckenna (2002).

É por esta via lançado ao utilizador o desafio de construção da sua autoapresentação, o seu eu online, através de um número limitado de caracteres e recursos simbólicos, nomeadamente fotografias, e será através dessa apresentação do self que o irão avaliar. Esta apresentação é assim uma dimensão central na procura de par (Chambers, 2013: 133).

\section{A apresentação do Eu}

Visões teóricas clássicas sobre a gestão das impressões e a importância do contexto

Promotor da corrente do interacionismo simbólico (Sandstrom el al. 2001) George H. Mead (1934, 1972) desenvolveu o seu trabalho tendo como foco uma abordagem sociológica que se focava na importância e na influência atribuída às relações interpessoais através do estudo dos significados que os sujeitos conferem às mesmas e que resultam da interação social. Importantes no seu trabalho são as ideias de papel social, de generalized other, que pode ser considerado como "qualquer outro que esteja ou possa ser um particular em detrimento da atitude de tomada de papéis" e de self- que poderá ser definido como uma construção mental do indivíduo sobre si próprio. Ou seja, a capacidade reflexiva que o indivíduo possui de se poder julgar a si próprio e se considerar a si mesmo como um objeto social. Como grande contributo, a escola do interacionismo simbólico ajuda a perceber como o self nunca é unilateral, mas, de forma dialética, também produto do social (Sandstrom el al., 2001: 219), forjado e reproduzido na interação social.

$\mathrm{Na}$ esteira de Mead, desenvolvendo os trabalhos sobre o self, mas com especial relevo dado à importância dos contextos e à apresentação temos Erving Goffman. O seu trabalho sobre a apresentação do eu representa um importante contributo teórico no estudo das relações interpessoais a um nível micro de análise, estudando os diferentes desempenhos de apresentação do eu no quotidiano sobre uma aproximação dramatúrgica da realidade social defendendo que os indivíduos atuam no seu dia-a-dia de forma estratégica, mais ou menos conscientemente, adaptando a sua fachada, definido como conjunto de ferramentas expressivas que o indivíduo utiliza seja de forma consciente ou inconsciente, para convencer a sua audiência durante o seu desempenho (Goffman, 1993: 34), aos diferentes contextos de interação por onde se movem (Goffman, 1993).

De forma holística, o fluxo expressivo dos atores engloba todo e qualquer elemento simbólico e comunicativo. Como tal, a atualização de status nas redes sociais online, não só o que se escreve, mas também como se escreve, o tipo de fotografias, posição corporal, vestimenta, entre tantos outros recursos simbólicos devem ser tomados como um exemplo do que pode ser considerado como a fachada nas redes sociais.

Atualmente nos estudos de media que abordam questões do eu estão presentes dois conceitos, a apresentação e a representação pelo qual, importa referir o contributo de Rettberg (2014) relativamente à reflexão entre os 
dois. Como a própria considera, não existe a necessidade de uma distinção estrita entre ambos já que na prática tanto elementos visuais como textuais serão analisados de ambas perspetivas não focando apenas o seu significado e conjunto de sinais, mas também o papel que o utilizador estava a interpretar no momento da construção do seu perfil bem como a quem este era dirigido (audiências).

\section{A apresentação mediada do eu, a audiência imaginada em contextos colapsados}

Como forma de aproveitamento deste manancial seminal, vários autores aplicaram (Ellison el al.., 2006; Gibbs, 2006; Cooley \& Smith, 2013; Casimiro, 2015; Patra, 2015) e por vezes adaptaram (Hogan, 2010), o quadro teórico de Goffman nos novos contextos online.

$\mathrm{Na}$ apresentação mediada do eu, como é o caso das redes sociais online, os perfis são elementos centrais na medida em que estes representam o utilizador, assim como são ponto de interação (boyd, 2010: 42), sendo contruídos de forma a serem vistos por uma audiência, que, à partida se desconhece.

E reside aqui a grande novidade e especificidade da apresentação mediada pelo online. Enquanto que na interação face-a-face os atores partilham e (re)conhecem o contexto espácio-temporal, no online, a mediação introduz um curto-circuito destas duas dimensões. Ao acionar um dado fluxo expressivo o ator não sabe: nem quando, nem quem, nem como este o irá interpretar, se é que haverá sequer audiência (boyd, 2010; Baym, 2011). A comunicação pode nem chegar a acontecer porque o recetor não recebeu a mensagem. Um qualquer conteúdo expressivo partilhado pode não chegar a toda aquela audiência que o utilizador considera desejada já que, "a audiência de um indivíduo é tipicamente muito menor do que todas as pessoas em todos os espaço e tempo é muito menor do que todas as pessoas em todos os espaço e tempo" (boyd, 2010: 43).

Ao refletir sobre estas temáticas, Litt (2012) refere-se a esta audiência como audiência imaginada, ou seja, a construção mental daqueles com quem se comunica (Litt, 2012: 331) ou nem se comunica. A mesma perceção funciona como uma leitura do contexto comunicacional e como tal orientadora da ação relativamente ao que 0 indivíduo acha que deve, ou não, partilhar, tendo em conta quem este imagina que a compõe, moldando-o e condicionando a sua autoapresentação.

A construção de perfis e a partilha de informação online tendo em conta uma ideia de audiência(s) condicionará, portanto, as práticas nas redes sociais online uma vez que promovem a construção da audiência imaginada em função das interações diárias dos utilizadores (Litt, 2016: 1). No entanto e com o objetivo de corresponder a determinadas expectativas da audiência imaginada ou do público o individuo poderá adequar a sua autoapresentação e o seu comportamento em função da mesma (boyd, 2010: 44).

Neste sentido, recorre-se ao conceito de perfil trabalhado desenvolvido por Silfverberg (2011) que se traduz no empenho dos indivíduos na construção dos seus perfis nas redes sociais online (Silfverberg, 2011: 1) e através do qual se assume que existe um conjunto de estratégias de autoapresentação nas plataformas de redes sociais com múltiplas possibilidades podendo os atores sentirem-se constrangidos nas suas escolhas e na gestão do seu eu (Uski, 2016: 450). Porém, esta gestão estratégica do perfil poderá ser desafiante na medida em que terá de ir ao encontro das expetativas de uma audiência heterogénea composta por elementos com diferentes vivências e perspetivas do que poderá ser socialmente correto ou expetável.

É então permitido aos utilizadores a construção dos seus perfis e re/apresentação de quem "são" através das ferramentas de comunicação baseadas na internet (Rui, 2013: 110) de acordo com as suas necessidades e objetivos e através de recursos comunicacionais como: imagens, textos, atualizando o seu estado, informando 
os outros sobre o que pensam, partilhando os locais que visitam e com quem, os seus gostos, interesses ou ideologias, entre outros. Por sua vez, este conjunto de informações partilhadas permite aos outros utilizadores construírem uma ideia sobre estes, que poderá ser determinante uma vez que "as estratégias de autoapresentação são especialmente importantes durante o início da relação, já que os outros vão utilizar essa informação para decidir se perseguir a relação" (Ellison, 2006: 417).

Ainda na perspetiva de Goffman (1993) o objetivo da autoapresentação será fazer com que o indivíduo seja distinguível com o propósito de provocar na audiência a impressão desejada, sendo digno de atenção em detrimento da restante audiência. Assim a autoapresentação deverá ser única e provocando impressões específicas nas audiências (Guadagno, 2012: 642).

No entanto, a construção de perfis nas redes sociais online não é um ato solitário já que nestas, determinado indivíduo ao qual outros estão ligados poderá partilhar informação sobre os restantes, seja no formato de uma imagem identificando-os na mesma ou partilhando determinada localização em que ambos se encontram. Para além destes aspetos, também podem exprimir vários tipos de sentimentos face a uma publicação, comentá-la ou partilhá-la conseguindo a publicação original chegar inclusive àqueles que o utilizador não conhece. Estas são consequência de como a internet está organizada, do potencial da mesma e da própria arquitetura das redes sociais online e das definições de privacidade de cada utilizador reduzindo assim o controlo da apresentação do eu (Rui, 2013: 110) e como efeito terá assim uma dificuldade acrescida em conseguir transmitir a imagem que pretende, na medida em que a "informação fornecida por outros é menos provável de ser manipulada, mais credível, e esta pode ter um maior impacto em como os utilizadores a quem os perfis pertencem, são percebidos" (Rui, 2013: 110).

Desta forma a internet permite, dentro de certos graus de autonomia, contruir a identidade como se de um conjunto de personagens se tratasse, que se podem representar tendo em conta o cenário em questão e a audiência que se quer impressionar. Essa identidade não precisa de ser estanque ou definitiva uma vez que a realidade online também não o é, sendo possível editar a informação tendo também em conta que a mesma não é contruída apenas pelo indivíduo (Baym, 2011:112).

Os conceitos desenvolvidos por Goffman podem ser transpostos ao ambiente mediado atual tendo em conta as especificidades próprias do social media e das redes sociais online. Neste contexto, Hogan (2010) que sugere que as questões da privacidade não se prendem apenas com o registo de forma anónima ou criação de um perfil alternativo que possa contrariar o papel que o indivíduo desempenha noutros círculos, mas sim através de um terceiro fator: o de ser selecionada a informação que se recebe ou se procura sobre este. Assim sendo, o autor distingue o conceito de performance aplicado às redes sociais através da introdução do conceito de exposição. Enquanto "as performances estão sujeitas a observações continuas e de auto monitoramento como meio de gestão das impressões, as exposições estão sujeitas a contributos seletivos ao papel de um terceiro" (Hogan, 2010: 384). Este terceiro elemento é aquele que o autor apelida de curador.

No caso específico das redes sociais de online dating, nomeadamente da rede em estudo, o curador assume a forma de filtro podendo o indivíduo escolher o género, a idade e a distância à qual se encontra o possível parceiro, juntamente com o estudo de preferências, gostos e interesses dos utilizadores propondo aqueles que consideram mais indicados, já que tem informação de qual poderá ser apropriado ao conteúdo ou não (Hogan, 2010: 380). Como tal, as sugestões de parceiros e o acesso ao perfil dos utilizadores estão relacionados e consequentemente condicionados pela informação que estes disponibilizaram no momento da construção do perfil e em função de escolhas anteriores, definição de preferências, histórico de ligações e consumos de tipos de conteúdos e outras variáveis de acordo com o algoritmo da rede. E este algoritmo vai analisando e definindo 
o que mostrar ao utilizador em função de como o conteúdo é integrado (Hogan, 2010: 384) não esquecendo que a arquitetura da rede condiciona as ações e consequentemente os resultados já que pode determinar as dinâmicas em função do design da plataforma (Gillespie, 2015: 2). Como tal, não se trata apenas de conteúdo resultante do desempenho, considerando-se que "este novo fenómeno não é necessariamente sobre a performance, mas sobre a arquitetura de mediação que encapsula e redistribui performances anteriores para mútuos e vários benefícios assíncronos" (Hogan, 2010: 384).

Contudo atendendo às circunstâncias da comunicação mediada em rede, poder-se-á dar o que boyd (2014), inspirada em (Meyrowitz, 1985; Wesch, 2009) apelidou de colapso dos contextos ocorrendo "quando as pessoas são forçadas a lidar simultaneamente com contextos sociais de outra forma não relacionados que estão enraizadas em diferentes normas e aparentemente exigem diferentes respostas sociais" (boyd, 2010: 31). Este colapsar de contextos à luz das redes sociais online poderá fazer com que a forma de expressão seja desafiante já que há que ter em conta a própria arquitetura e funcionamento das redes sociais online que agregam vários contextos e círculos sociais distintos.

Neste sentido, espera-se que o papel desempenhado pelo ator e sua a fachada pessoal seja minimamente coerente, na medida em que é expectável que "a relação entre aparência e modo seja de confirmação e consistência" (Goffman, 1993: 37), sendo que ao mesmo tempo, esta deva ser minimamente adaptado aos diferentes contextos e redes sociais e respetivos papéis associados do mesmo sujeito. Se por um lado se espera o mínimo de coerência, uma vez que é expectável que a autoapresentação do indivíduo esteja em concordância com as fotografias do seu perfil e consequentemente como este se expressa, da informação transmitida e do conteúdo das mensagens trocadas. Por outro, algum do fluxo expressivo público poderá não ser adequado a contextos para além da rede de online dating.

Esta coerência não se aplica apenas aos elementos da autoapresentação que constam naquela rede de online dating, mas também a outras redes sociais online já que, através da internet o indivíduo pode procurar informação complementar de forma a completar a construção do eu do outro. Encontra-se aqui um dos grandes desafios da gestão das impressões em contextos colapsados múltiplos e diferenciados e com audiências imaginadas.

\section{Género}

Um ponto central da identidade, seja na construção e apresentação do eu online, seja na procura de outros utilizadores nas redes sociais é a apresentação do género. Uma vez que é uma variável com importante peso no estudo importa abrir espaço no quadro teórico às questões de género. Num primeiro momento será importante destrinçar duas dimensões de categorização que desde a década de 70 entraram no discurso académico: sexo e género, e, de forma encadeada, masculinidade e feminilidade.

Designa-se por género, a masculinidade ou a feminilidades convencionadas socialmente (Holmes, 2007: 2; Lips, 2013). Tal construção contrasta o termo utilizado para designar as diferenças biológicas e fisiológicas entre homens e mulheres: o sexo. Trata-se deste modo de diferenciar determinadas variáveis de ordem naturalbiológica, e as construções simbólico-culturais que com elas se entrelaçam, sem que os aspetos dessa mesma ordem correspondam ou representem aquelas variáveis.

Para uma proposta de definição mais multidimensional e robusta de género: este "designa o conjunto de significados e valorizações associados, num certo tempo e espaço social e geográfico, às categorias "feminino" 
e "masculino", e os processos, discursos e estruturas através dos quais se (re)produzem e negoceiam, de forma contínua, mas variável, diferenciações e hierarquias entre pessoas e "coisas" com base nessas categorias" (Pereira, 2012, 35).

Entenda-se desta forma o género como um processo dinâmico e performativo (Butler, 1988) de (re)construção sociocultural - embora comummente julgado como natural e como tal naturalizado quotidianamente - abstrata de classificação e diferenciação social. A distinção dos factos biológicos do sexo e dos factos culturais e papéis sociais do género abriu caminho para a interpretação do género como um sistema de símbolos e significados (Holmes, 2007) influenciadores e influenciados por práticas e representações. A diferenciação entre os sexos é extrapolada para a ordem simbólica, sendo (re)construídos significados sociais para as diferenças anatómicas. É justamente, a partir desta primeira distinção conceptual entre sexo e género, que estes aspetos se tornam operativos para outras distinções social e culturalmente relevantes. Neste seguimento, e mais do que uma lógica de tradução, as relações entre sexo e género devem ser compreendidas como formando um sistema no qual uma matriz social e cultural, própria de uma época e de uma sociedade, define o masculino e o feminino. Ou seja, sendo uma categoria negociada e (re)contruída é social, cultural e historicamente contingente. De facto, há uma representação social hegemónica dos sexos, masculinidades e feminilidades que se estratificam de forma desigual e assimétrica (Amâncio, 1994: 179) num esquema complexo de associações comummente partilhadas de certos valores, atitudes, expectativas e comportamentos, atribuídos quer a homens quer a mulheres, resultando numa divisão diferenciada de papéis. Desta forma a categoria de ser homem ou mulher é uma condição (re)produzida pela cultura, que implica a construção de dicotomias como público/doméstico, natureza/cultura, produção/reprodução.

Claro que por sua vez importa não cair em determinismos sociais, delegando poder único às estruturas sociais e descurando a agência individual e uma relativa autonomia. Não há só reprodução social. Será para tal produtivo no decorrer desta senda analítica reforçar a dimensão performativa do género percebendo que este não é algo que se tem, mas que se faz (Pereira, 2012) sendo constantemente negociado na dimensão micropolítica, ou seja, nas interações quotidianas e até no plano individual. Da mesma forma devemos ainda na análise não incorrer em reificações ou essencialismos e "não tomar dualismos como pressuposto, como a priori, a partir do qual se estudam os objectos" (Pereira, 2012: 177).

\section{Masculinidade e Feminilidade}

A masculinidade define-se, genericamente, como sendo a incorporação da estrutura de relações sociais, em que características hegemónicas do homem subsistem, estabelecendo-se convenções senso-comunais (Amâncio, 1994; Almeida, 1995). Por seu turno a feminilidade remete para os estereótipos e matrizes de valores associados ao sexo feminino.

As noções de masculinidade e feminilidade constroem-se e reproduzem-se quotidianamente, pela divisão do trabalho, pela socialização na família e escola, pelas formas ritualizadas de sociabilidade e interação e, sobretudo, pelos signos do género (noções de pessoas, do corpo, das emoções e sentimentos). Falemos, no entanto, não de uma masculinidade ou feminilidade no singular, mas sim de masculinidades e feminilidades no sentido mais plural, plurifacetado, adstrito aos contextos e complexo do seu termo. Podemos sim, falar de masculinidades hegemónicas (Connel, 2005a e 2005b) enquanto ideal de referência comportamental e que atua como "o modelo central que subordina as masculinidades alternativas (de pessoas, grupos ou sociedades), e 
que é modelo da dominação masculina, intrinsecamente monogâmica, heterossexual e reprodutiva" (Almeida, 1995: 155). São assim "padrões de conduta e personalidade com estatuto muito elevado, que servem como modelo de referência à regulação e avaliação dos comportamentos. São as formas de masculinidade dominantes num dado grupo ou contexto, não no sentido de serem as mais comuns, mas porque são consideradas mais legítimas e desejáveis dos que as restantes formas de masculinidade" (Pereira, 2012: 136).

Ora este modelo é imposto não tanto pela força física, mas sim através de uma dominação, e, portanto, violência, simbólica (Bourdieu, 2013). Sendo perpetuada através de instituições como a escola ou pelos media que (re)criam convenções mais consensuais acerca do que um homem é, deve (e pode) ser e fazer. A hegemonia de algumas "masculinidades" sobre outras dá-se nesse sentido: ela é exercida quotidianamente (práticas sociais), produzindo saberes sobre o homem que se reforçam e se constroem nas relações formadas entre homens e homens, e, entre homens e mulheres, no seu quotidiano e através da história. Esses saberes são produtores de efeitos de poder, reforçam e integram as práticas de dominação e submissão, e no seu movimento também alteram e subvertem essa dominação.

A rematar será imperativo reforçar o carácter assimétrico entre masculino e feminino, ou seja, são diferentemente valorizados (Amâncio, 1994) e que "o dominado tende a assumir sobre si próprio o ponto de vista dominante" (Bourdieu, 2013: 102).

\section{Os utilizadores portugueses e as redes de online à luz dos dados secundários.}

Em Portugal existem alguns estudos sobre temas como a dicotomia online/offline, questões de género nas plataformas de online dating ou cybersex. Ainda assim existe uma lacuna na academia no que diz respeito a estudos concretos e exclusivos sobre a realidade do online dating em Portugal, nomeadamente a estratégias de apresentação e representações do eu. Estes estudos vêm reclamar a sua importância na medida em que em Portugal se tem vindo a registar um aumento no uso de utilizadores da internet. De acordo com dados recentes do INE (2016), 74\% das famílias Portuguesas têm acesso à internet em suas casas, sendo que o aparelho que mais utilizam para fazê-lo é o telemóvel/smartphone (78\%) seguindo-se o computador portátil (73\%). Estes indicadores vêm justificar de alguma forma a tendência para o uso de aplicações móveis e sustentar a importância deste artigo ter como objeto de estudo uma plataforma móvel. De entre aqueles que têm acesso à internet, a área metropolitana de Lisboa, local onde foi realizado o presente estudo, é a que regista um maior número de famílias com internet nas suas casas (82\%).

No que aos géneros diz respeito, o masculino tendo a apresentar taxas de utilização superiores às do género feminino - $72 \%$ versus $69 \%$, sendo que a sua utilização é mais frequente na população até aos 54 anos, assim como em sujeitos que tenham completado o ensino secundário (96\%) e o ensino superior (98\%).

Relativamente ao uso das redes sociais e de acordo com os dados do inquérito "Sociedade em Rede" (Cardoso, 2014), independentemente do objetivo de uso e da frequência das redes sociais, estas são utilizadas maioritariamente pelo género masculino cuja média de idades se situa nos 31 anos. Estes dados vão ao encontro da informação disponibilizada pela publicação GlobalWebIndex (McGrath, 2015) e segundo a qual, dentro do universo norte-americano daqueles que utilizam o Tinder, $62 \%$ são do género masculino e $38 \%$ do género feminino e a maior percentagem de utilizadores (48\%) têm idades compreendidas entre os 25 e os 34 anos.

A razão da escolha ter recaído sobre os utilizadores do Tinder deve-se a características próprias da aplicação, nomeadamente funcionar apenas em smartphones, com base na geolocalização, permitir somente a 
comunicação após um match e por nos três anos que se seguiram à sua implementação ter tido um grande crescimento no mercado português e internacional estimando-se se que atualmente, e de acordo com dados divulgados pela própria empresa, a aplicação tenha mais de 50 milhões de utilizadores (Bilton, 2014) registados em todo o mundo.

\section{Metodologia}

Pergunta de partida, objetivos e questões de pesquisa subsidiárias

No seguimento e aplicando o enquadramento teórico, consegue-se compreender que a autoapresentação possui extrema relevância nas plataformas de online dating, fazendo com que o utilizador pondere ou não entrar em contacto ou que o seu perfil seja sugerido a outros utilizadores. É também com base nesta autoapresentação mais ou menos elaborada e consciente, que os utilizadores constroem a sua apresentação mediada e imaginada sobre o outro, fazendo com que se avalie o indivíduo de forma multidimensional num continuum com polos como: interessante ou desinteressante, atraente ou não, indo ou não ao encontro de um conjunto de ideais construídos que permite qualificá-lo como alguém com quem se deseje estabelecer um relacionamento amoroso. Essa relevância conduz à construção e definição da pergunta de partida para o presente artigo: como é que os utilizadores portugueses das plataformas de online dating móveis se apresentam nas mesmas? O objetivo principal da realização do mesmo é, entre os utilizadores portugueses do Tinder, investigar e tipificar os dados que estes consideram importantes revelarem sobre si nas suas estratégias de construção de perfis ou seja, como é construída a sua autoapresentação, sendo de seguida crivados por género. Por autoapresentação compreende-se neste artigo todos os recursos simbólicos como: texto, fotos e outros elementos comunicacionais como emojis, a que os indivíduos recorrem para construírem os seus perfis.

Para além do objetivo principal, definiu-se ainda um conjunto de objetivos secundários importantes para contextualizar a análise e compreender eventuais padrões e regularidade sociais, mas também especificidades. Desdobrando o fluxo expressivo por elementos visuais e textuais, mas adotando sempre uma visão holística:

1. Analisar que atributos ou características os indivíduos parecem revelar através das fotografias para construírem a sua apresentação.

2. Verificar se existem diferenças no número, tipo de fotografias partilhadas e texto.

3. Identificar as características sobre si que os diferentes géneros parecem enaltecer e considerar mais importantes no momento da sua autoapresentação.

De acordo com os objetivos estipulados, estabeleceram-se as seguintes questões de pesquisa subsidiárias:

1. Qual a importância atribuída ao conteúdo visual e conteúdo escrito?

2. Que tipo de informações são mais partilhadas?

3. O que é que os utilizadores pretendem revelar sobre si através das imagens partilhadas?

4. São registadas diferenças na estratégia de autoapresentação em função do género?

5. Algum dos géneros incentiva mais ao contacto do que outro? 
As questões colocadas pressupõem à partida a hipótese de que a variável género poderá representar diferença aquando da construção de perfis e consequentemente na autoapresentação, e são essas diferenças que se pretendem investigar ao longo da análise de resultados.

\section{Procedimento Metodológico}

Tendo em conta os objetivos e as questões de pesquisa realizou-se um estudo de caso exploratório para o qual se recorreram a técnicas de recolha e análise de dados secundários de enquadramento bem como dados primários - observação e análise de conteúdo visual e textual extant (Salmons, 2016). A saber, implica a recolha e uso materiais existentes, dados encontrados e não produzidos pelo investigador - a chamada found data (Banks, 2001; Jensen, 2012: 287-288; Rose, 2001), e sem a influência do investigador ou contacto com os participantes.

O método com recurso a técnicas distintas foi mobilizado com o propósito de contextualizar a população em estudo, saber mais sobre a rede e utilizadores em estudo através da realização de entrevistas e já enformados pelos conhecimentos resultantes partiu-se para a observação online recolhendo fotografias e informação textual disponibilizadas na autoapresentação dos perfis dos utilizadores portugueses do Tinder analisando-os posteriormente de forma quantitativa e qualitativa.

Desta forma com de acordo com a classificação das estratégias mistas de Bryman (2012: 632), refinada posteriormente por Creswell (2014: 15-16), a estratégia mobilizada neste artigo pode ser descrita como método misto explanatório e sequencial(Creswell, 2014: 224-225). Isto é, esta estratégia mista consistiu numa primeira aproximação qualitativa, seguida de uma abordagem quantitativa e qualitativa de acompanhamento e aprofundamento no terreno de dimensões evidenciadas pela primeira recolha de dados, sendo, contudo, dado maior relevância à técnica de análise de conteúdo visual e escrito.

\section{Análises Qualitativa e Quantitativa}

\section{Entrevistas}

Com o propósito de uma aproximação à relação dos utilizadores com a aplicação, das suas motivações, expectativas e perceção do que é valorizado em perfis sugeridos realizou-se um conjunto de 10 entrevistas. Através da aplicação destas, considerou-se ser possível reconstituir, ainda que de forma não generalizável, alguns aspetos como: quais as informações que os utilizadores valorizam nos perfis ou com que base em que dados é que estes tomam a sua decisão.

A amostra, constituída por utilizadores do Tinder portugueses e a viver em Portugal, obtida por conveniência e angariada através de bola de neve, era composta por 10 sujeitos, 5 do género masculino e 5 do género feminino, cuja média de idade se situava nos 31,2 anos, residentes em Lisboa e que responderam às entrevistas entre Maio e Setembro de 2016.

De forma estratégica e fazendo uso de alguma reflexividade sobre a delicadeza do tema deste artigo - uma vez que expõe aspetos da vida privada - e potenciais implicações metodológicas, as recolhas do discurso focaramse na perspetiva dos utilizadores face ao perfil dos outros e não relativamente ao perfil do próprio. Não obstante, e como já esperado, constatou-se alguma resistência na angariação de utilizadores disponíveis para a realização 
das entrevistas pessoalmente, ainda que fosse garantido a confidencialidade dos mesmos. Para se contornar este obstáculo, disponibilizou-se a mesma através de um formulário online para que os sujeitos pudessem responder anonimamente e sem qualquer contacto pessoal com o investigador. Note-se que se teve em conta, nesta situação de compromisso inevitável, uma potencial perda da riqueza dos dados, estando os resultados das mesmas condicionados pela técnica utilizada uma vez que a realização de uma entrevista online por escrito não produziu um fluxo discursivo tão volumoso e espontâneo como quando poderia ter resultado ao realizá-la pessoal e oralmente. Não obstante, e equacionadas as vantagens e limites desta técnica de inquirição assíncrona (Hooley el al., 2012) esta demonstrou ser relevante e vantajosa na recolha de dados e na compreensão geral do fenómeno ainda que as referências às mesmas na discussão de resultados fossem por vezes meramente ilustrativas.

\section{Recolha de dados existentes online e análise de conteúdo (visual e textual)}

Posta esta primeira exploração e introdução através das entrevistas fez-se uso de um método de recolha online de tipo "extant" (Salmons, 2016). Através da implementação desta técnica, foi permitido observar os utilizadores de Tinder no contexto "natural" (a aplicação) evitando que se alterassem comportamentos resultando numa descontextualização ou alteração dos mesmos, sendo assim possível extrair informações que com outras técnicas poderiam ser mais complexas e sujeitas a um potencial enviesamento.

Procedeu-se à coleta de dados de uma amostra de 200 perfis. Na impossibilidade de acesso a dados concretos sobre qual o número de utilizadores portugueses registados no $\operatorname{Tinder}^{1}$, foi recolhida uma amostra por conveniência, constituída por 200 sujeitos, 100 pertencentes ao género feminino e 100 perfis pertencentes ao género masculino perfazendo o total de 701 fotografias analisadas e 87 textos. Esta amostra aleatória teria de cumprir um conjunto de parâmetros de procura e eleição dos perfis:

- $\quad$ Género: procurou-se sempre o oposto ao do perfil em utilização.

- $\quad$ Faixa etária: não foi balizada com o propósito de não condicionar o algoritmo.

- Distância: estabeleceu-se um perímetro de procura máximo de $10 \mathrm{~km}$ do local onde se encontrava o investigador limitando-o ao centro de Lisboa.

- $\quad$ Fotografias: foram recolhidas todas as fotografias que compunham o perfil.

- $\quad$ Nacionalidade: foram descartados os perfis cujos utilizadores afirmavam serem de outra nacionalidade que não portuguesa, já que os objetivos do estudo se cingiam aos portugueses.

A recolha destes foi efetuada em (nos dias 16, 22 e 23) Novembro de 2016 e os dados codificados foram analisados através do programa estatístico SPSS para a sua vertente mais quantitativa, sendo depois realizada uma análise em moldes qualitativos, quer do contexto visual quer do contexto escrito.

\footnotetext{
${ }^{1}$ Contactou-se o Tinder através de emaile da plataforma LinkedIn, explicando o teor e objetivos da abordagem, mas não se obteve qualquer resposta.
} 


\section{Considerações éticas e deontológicas}

Apesar de, em linhas gerais, as preocupações éticas serem partilháveis com a pesquisa social offline, a investigação online introduz novos desafios éticos, nomeadamente por baralharem as fronteiras entre público/privado, publicado/não publicado, local/internacional, profissional/amador (Hooley el al., 2012: 26-27). Desta forma, foram tidas em conta considerações éticas e deontológicas nas metodologias e técnicas utilizadas na recolha de dados uma vez que "sites e páginas web são fontes potenciais de dados no seu próprio direito e podem ser considerados como material potencial, tanto para análise quantitativa e qualitativa de conteúdo" (Bryman, 2012: 654).

O facto de os dados estarem acessíveis poderá levantar dúvidas na determinação de se o conteúdo é público ou privado e "para determinar se o consentimento informado é requerido, é primeiro necessário decidir se as publicações numa comunidade online são comunicações públicas ou privadas" (Eysenbach, 2001: 1104). Ainda assim, no caso concreto do Tinder e devido à natureza da plataforma, não é possível obter consentimento informado por parte dos utilizadores já que não existe a possibilidade de entrar em contacto com os mesmos. No entanto, o registo na plataforma possibilita o acesso a toda a informação partilhada pelos utilizadores não existindo diferentes graus de privacidade na partilha da mesma tal e como em outras redes (veja-se o Facebook por exemplo) sendo que esta apenas proíbe o uso dos dados dos seus utilizadores com o intuito comercial.

Dentro das dinâmicas da investigação online também se compreende que determinadas ações podiam resultar numa quebra de confiança na comunidade, seja pelo conhecimento da presença de um investigador resultando na alteração de dinâmicas existentes ou, no caso do Tinder, a presença de um perfil pudesse suscitar um eventual interesse por parte dos utilizadores criando expetativas não correspondidas. Assim sendo, e com o intuito de efetuar o registo na aplicação e recolher informação relativa aos perfis dos utilizadores sem mitigar a comunidade, optou-se pela criação de dois perfis (um masculino e um feminino), com nomes comuns (António e Maria), com idade pertence à faixa etária do maior grupo de utilizadores da rede 25 - 34 anos, segundo os dados do GlobalWebIndex (2015), sem fotografias e sem informação extra partilhada no respetivo apartado. Partiu-se do princípio que com recurso a um perfil sem autoapresentação (fossem dados visuais ou escritos), ligações em comum com outros e que não interagisse com os outros utilizadores, se minimizasse qualquer dano possível. Esta necessidade da criação de novos perfis, também se deveu ao facto de se considerar que o registo na plataforma com o perfil do investigador iria condicionar resultados, já que este tem toda uma história online criada, com interações, amigos ou interesses, permitindo também preservar a identidade e privacidade do mesmo. Por fim e devido a características próprias do funcionamento da aplicação não foi possível entrar em contacto com os utilizadores de forma a solicitar consentimento informado, no entanto, e apesar de terem sido efetuadas capturas de ecrã das fotografias e conteúdo, considera-se importante esclarecer que os perfis foram anonimizados e as fotografias pixelizadas com o propósito de respeitar a privacidade garantido a sua confidencialidade.

Relativamente às entrevistas, e devido ao facto de estas serem distribuídas pela internet através do envio de um link, não foram registados dados pessoais como correio eletrónico ou nome daqueles que responderam às mesmas, garantido assim o anonimato. 


\section{A componente visual}

Atribuiu-se especial enfâse (até pelo desequilíbrio - foram bastantes os perfis apenas com imagem e sem texto - 113) à análise do conteúdo visual das fotografias escolhidas pelos utilizadores - tal como já efetuado, entre outros, por (Humphreys, 2006; Casimiro, 2015) e que pode ser definida, na sua vertente mais quantitativa, como um método sistemático de observação com vista a testar hipóteses. Remetendo para uma definição mais precisa: "é um procedimento empírico (observacional) e objetivo para quantificar representações "audiovisuais" (incluindo verbais) gravadas, utilizando categorias fiáveis, explicitas e definidas ("valores" em "variáveis" independentes)" (Bell, 2008:13). Ou seja, de acordo com (Bell, 2008:16) é uma técnica que tende a ser orientada pelas questões de partida e hipóteses comparativas e privilegia a análise e posterior quantificação de conteúdos classificados por diferentes categorias prévias.

Cada vez que a aplicação sugeria um perfil que se enquadrava nos parâmetros mencionados anteriormente, foram efetuadas capturas de ecrã tanto dos dados como das fotografias para que depois pudessem ser codificados na grelha de observação construída para o efeito. Após concluída a recolha, o perfil foi remetido para a esquerda do ecrã para que este não voltasse a ser sugerido e se recusasse o match. Após recolha, e numa primeira imersão no material foi definido um manual de codificação para a vertente mais quantitativa.

Na fase de codificação do material - tarefa replicável para o estudo ser confiável (Rose, 2001: 62) e realizada em várias fases (Saldaña, 2009) com vista a uma crescente sistematização e condensação donde adveio a necessidade de concordância entre codificadores/investigadores, a chamada (inter)coder reliability foi assegurada realizando o processo de codificação pelos dois codificadores conjuntamente.

De forma interligada e não estanque após a codificação foram analisados os dados e tentou-se perceber quais os temas que emergiram da análise e potencias padrões na amostra.

Como forma de potenciar a descoberta combinou-se uma estratégia de codificação mais estrita e de cariz quantitativo com uma codificação mais qualitativa e flexível. Na etapa quantitativa fez-se uso de uma grelha de observação com 86 variáveis fechada e construída para o efeito de acordo com o referencial teórico, objetivos da investigação e dados recolhidos onde eram registados um conjunto de informações que os utilizadores partilhavam nos seus perfis, fossem fotografias ou texto. Na fase mais qualitativa, e apenas dedicada à vertente visual, emergiram num primeiro ciclo de codificação 222 categorias, sendo de seguida recodificadas e refinadas em 18 categorias - tal como aconselhado por (Saldaña, 2009; Creswell, 2014; Salmons, 2016) - sempre pelos dois investigadores.

A utilização articulada destas técnicas permitiu um desenho da pesquisa mais capaz de dar resposta às questões colocadas e o levantar de considerações face aos resultados encontrados, tendo sempre em conta enquadramentos teóricos prévios, mas, ao mesmo tempo, abertos à realidade que se ia descobrindo, numa lógica de pesquisa de descoberta não só indutiva e/ou dedutiva, mas também: abdutiva (Blaikie, 2000).

\section{O perfil dos utilizadores portugueses de Tinder}

\section{Caracterização geral da amostra entrevistada}

Os entrevistados eram utilizadores do Tinder em média há 1,4 anos e os objetivos de registo apontados foram: curiosidade, procura de novas amizades e o desejo de conhecer pessoas com quem sair ainda que esse não tenha o objetivo inicial quando se registaram - "No início foi curiosidade, mas depois comecei a interessar-me 
em conhecer outras pessoas" (Anónimo 9, 31 anos), sendo que dois assumiram que estavam à procura de parceiro. As suas decisões eram maioritariamente tomadas com base nas fotografias como se verificou no discurso de um dos utilizadores: "Se considerar a foto de perfil interessante vou ver mais fotos e ler a informação partilhada" (Anónimo 9, 31 anos). No entanto grande parte dos entrevistados também referiu a importância da informação considerando perfis mais interessantes aqueles que disponibilizavam não apenas fotografias, mas também informação tal e como indicou o discurso de um "Muito mais interessante um perfil que contenha fotos e informações pois assim fico a saber mais, mas também posso com essa informação pesquisar a pessoa noutras redes e ficar a saber mais" (Anónimo 6, 35 anos). Note-se que tal procura articulada através de vários media é uma tendência encontrada noutros estudos (Chambers, 2013: 132).

\section{Caracterização geral da amostra analisada}

Tal como já referido a amostra online em estudo foi composta por 200 perfis, 100 pertencentes ao género feminino e 100 pertencentes ao género masculino, computando um total de 701 fotografias e 87 textos de perfil. As idades dos utilizadores da mesma variavam entre os 18 e os 57 anos, com uma média de 34,1 anos sendo o desvio padrão de 7,5. A média de idades do género feminino situou-se nos 34,2 anos e a do género masculino situou-se nos 33,4 anos.

É importante mencionar que a média de idades estava condicionada pela ação do algoritmo quer em função da idade dos perfis criados pelos investigadores (34 anos para perfil masculino como para o perfil feminino) quer das escolhas dos outros utilizadores. Tal e como defende Hogan (2010) ao argumentar que o algoritmo, cunhado por este como curador, é mediador seja no papel de filtro, de procura ou de escolhas.

\section{As fotografias - a componente visual}

Tal como notado no enquadramento teórico, tratando-se de uma comunicação mediada a apresentação fotográfica, é fulcral na gestão das impressões, e em contextos de online dating o recurso a estas tem acelerado a popularidade destas plataformas (Chambers, 2013). A componente visual, contrariamente à componente escrita, ajuda mais rapidamente na criação de uma impressão e ao contrário dos textos contribui significativamente para atrair potenciais parceiros (De Vries, 2007). Estudos anteriores, como (Cash el al.., 2004; Humphreys, 2006; Siibak, 2009; De Vries, 2010; Toma \& Hancok, 2012, Casimiro, 2015; Chappetta, 2016, Miguel 2016) demonstraram não apenas importância das fotografias, assim como deste tipo de autoapresentação, e encontraram diferenças entre géneros e idades.

\section{Número de fotografias}

Do total de 200 perfis, $25 \%$ dos utilizadores construíram o seu perfil com 4 fotografias. A média de fotografias partilhadas situou-se nas 3,5 sendo que não se registaram diferenças acentuadas em função dos géneros (3,4 fotos género feminino e 3,6 género masculino). Respeitante à composição, aquela a que $54,4 \%$ dos utilizadores recorreu é a de primeiro plano. Consideraram-se diferentes planos, adaptados de Wohigemuth (2005), em que se estipulou plano geral aquele onde se mostrava todos os elementos da imagem, plano americano onde 
surgiam pessoas com ângulo desde a cabeça à altura dos joelhos, primeiro plano mostrava a zona da cabeça até à dos ombros e detalhe mostrava pormenores.

Na rede em análise, o utilizador pode construir o seu perfil com um máximo de seis fotografias, no entanto de entre a amostra apenas $15 \%$ dos utilizadores optou por fazê-lo. Na tabela 1 pode verificar-se a relação entre o número de fotografias que compunham o perfil, a sua frequência e a correspondente percentagem de utilizadores.

Tabela 1: Número de fotografias, frequência absoluta e relativa por total de utilizadores

\begin{tabular}{|c|c|c|}
\hline $\begin{array}{c}\text { Número de } \\
\text { fotografias }\end{array}$ & Frequência & $\begin{array}{c}\% \\
\text { Utilizadores }\end{array}$ \\
\hline 1 & 28 & $14,0 \%$ \\
\hline 2 & 33 & $16,5 \%$ \\
\hline 3 & 34 & $17,0 \%$ \\
\hline 4 & 50 & $25,0 \%$ \\
\hline 5 & 25 & $12,5 \%$ \\
\hline 6 & 30 & $15,0 \%$ \\
\hline $\mathrm{n}$ & 200 & $100,0 \%$ \\
\hline
\end{tabular}

\section{Sozinho ou acompanhado?}

De entre as 701 fotografias analisadas, a grande maioria 67,8\% preferiu partilhar fotografias em que se encontrava sozinho. No entanto, 23,3\% dos utilizadores optou por partilhar imagens com mais de uma pessoa. De entre estas emergiram, sobretudo, fotografias nas quais os utilizadores estavam com indivíduos do mesmo sexo e oposto, fotografias em grupos cuja análise remetia para situações de convivialidade e mesmo hedonistas, ou seja, práticas eminentemente sociais. Por seu turno, nas configurações menos usais, mas ainda dentro da categoria das pessoas que não estavam sozinhas, encontraram-se também fotografias cujos utilizadores estavam com crianças, em menor número que as situações referidas anteriormente, é certo, mas presentes. A análise revelou ainda um número residual de utilizadores, 0,9\% que não aparecendo sozinhos optaram por partilhar fotografias com animais sendo estes na sua maioria domésticos tais como cães e gatos.

\section{Identidade: self disclosure e anonimato}

Uma dimensão pertinente para análise prendeu-se com o anonimato online numa rede de encontros. Do corpus de fotografias analisadas e tal como indicado na Figura 1, foi possível constatar que em 14,1\% das mesmas o utilizador optou por partilhar conteúdo no qual se encontra não identificável. De entre esse conteúdo aquele que mais sobressaiu foram conteúdos visuais não fotográficos, mas sim gráficos - fossem estes na forma de ilustrações, frases feitas, animais, símbolos clubistas ou símbolos ligados ao esoterismo - o símbolo Om ॐँ. 
Figura 1: Percentagem de fotos identificáveis versus não identificáveis $-n=701$

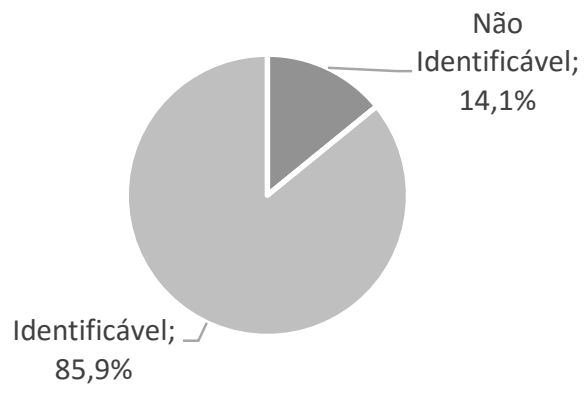

Focando naqueles que partilharam conteúdo não identificável, $8 \%$ da amostra $(n=200)$ fá-lo em todas as fotografias, configurando como tal um perfil totalmente anónimo. As percentagens eram idênticas em ambos os géneros sendo que essa variável não parecia explicar a escolha pelo anonimato nesta rede.

\section{Propriedades formais da fotografia}

Tal como Rose (2001) refere, a análise visual teve presente, entre outras dimensões, as propriedades formais da fotografia, sendo que uma delas passou pela composição. Dos utilizadores da amostra que partilharam fotografias de ou com pessoas (93\%) e no que diz respeito à composição fotográfica escolhida e não "original", na medida em que o enquadramento utilizado poderá ter sido ou não o original da fotografia, como se pode ler na Figura 2, 54,4\% elegeu o "primeiro plano".

Assim sendo, ao emergir como o tipo de composição fotográfica mais utilizada, poderá ser com base nesta que os utilizadores tomavam a decisão de saber mais ou aceitar/rejeitar o perfil. Este facto foi também comprovado com os dados das entrevistas, nas quais sujeitos argumentaram que a primeira fotografia, e ainda que esta possa não ser o único fator por base na sua decisão, é a mais importante assim como apontarem que o tipo de fotografia que preferiam ver nos perfis eram de rosto a as de corpo.

Figura 2: Composição fotográfica $-n=701$

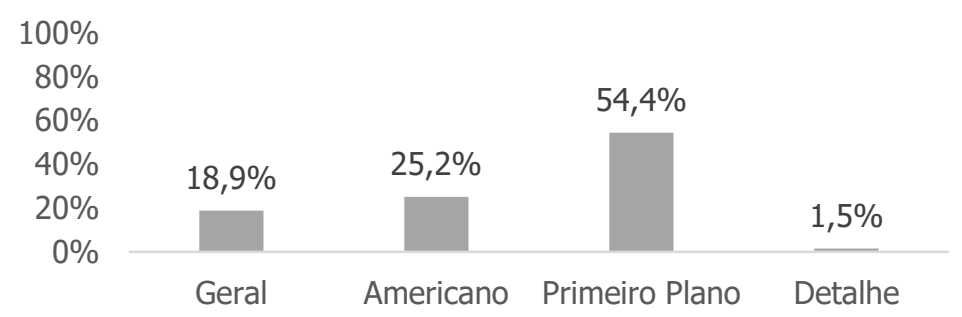

É pertinente adiantar que a escolha de planos com diferentes enfoques na figura humana, introduziu implicações na profundidade da leitura de dados contextuais. Como tal na catalogação de imagens centradas no indivíduo não se realizou a classificação de aspetos tão finos com a inclinação da cabeça ou curvatura dos lábios que influenciam a forma como se julga e se classifica socialmente os indivíduos (Vernon, 2014). Sendo assim 
comparativamente menos rica do que a leitura de indícios em fotografias com planos focais mais largos, afastados e enquadramentos mais amplos - logo à partida com mais componentes de informação visual. Esta decisão deveu-se a um questionamento da pertinência do mesmo e para evitar o perigo de ser esmagado por um manancial de dados incomensurável.

Ainda respeitante à composição fotográfica, 25,2\% dos utilizadores partilharam imagens com plano americano, $18,9 \%$ cujo plano era geral e 1,5 cujo plano era de detalhe. Apesar do enquadramento a que os utilizadores mais recorreram ser o de primeiro plano, as restantes composições tinham um grande peso.

Não obstante, para além da composição importa estar igualmente atento a outras características intrínsecas às imagens (Rose, 2001). Assim sendo, ainda que a grande maioria das imagens partilhadas retratasse a realidade capturada a cores foi possível encontrar várias fotografias a preto e branco, bem como fotografias manipuladas com diferentes tipos de filtros e edições, bem como a justaposição de elementos como bandeiras ou ilustrações. De entre os utilizadores que optaram por partilhar fotografias com pessoas, 79,8\% das vezes, estas não eram integrantes na fotografia por estarem em segundo plano ou ainda que estando em primeiro plano foram, em parte, desenquadradas ou eliminadas posteriormente da fotografia. Exatamente o oposto se verificou quando eram partilhadas fotografias de pessoas com animais, em 92,9\% dos casos estes eram integrantes nas mesmas.

\section{Exposição do Corpo}

Chambers (2013: 137) refere que o corpo tende a estar hiperpresente em contextos de online dating, sendo parte fulcral das leituras do eu, e dos outros. Como tal decidiu-se isolar a percentagem de utilizadores que partilharam fotografias nas quais existe uma exposição do seu corpo. Foram 9,8\% dos utilizadores que o fizeram sendo que, em $2 \%$ dos casos essa exposição surgia na primeira fotografia. De entre a exposição, o "peito" é a zona corporal que mais apareceu com 31,3\%, seguindo-se fotografias em "bikini" 18,8\% e em calções de banho $14,1 \%$ tal e como se pode observar na Figura 3. É importante ter em conta a sazonalidade das fotografias bem como o contexto em que estas são tiradas.

Figura 3: Exposição do corpo $n=64$

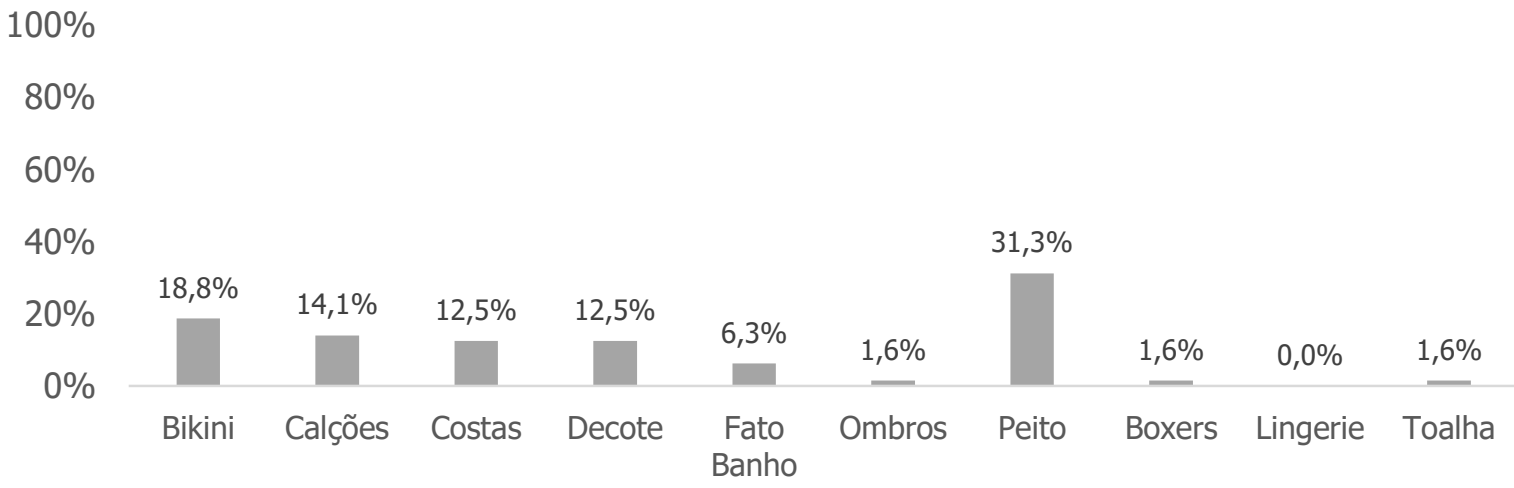

É também importante referir, e ainda que existisse uma exposição do corpo, as fotografias pertencentes a esta categoria são pouco explícitas não se denotando uma sensualidade ou erotismo explícito nas mesmas - o que poderia ser expectável tendo em conta a rede. De acordo com os estudos de Miguel (2016) a não partilha de 
fotografias consideradas sexy poderá estar relacionada com o tipo de rede, a sua audiência e a perceção que esta poderá relativamente ao utilizador já que resultados dos seus estudos indicaram que participantes descartaram utilizadores que recorriam a fotos sexy devido a não parecerem intelectuais ou respeitáveis (Miguel, 2016: 8).

Esta exposição do corpo e intimidade parece ser de alguma forma expectável pelos utilizadores na medida em que um dos entrevistados considerou que as fotografias mais interessantes eram aquelas consideradas mais íntimas.

Porém as próprias affordances da rede puderam de alguma forma limitar o resultado já que a criação do perfil no Tinder é realizada através do Facebook e que esta rede social tem uma política assumidamente discriminatória uma vez que o algoritmo não permite a publicação de fotografias de indivíduos do género feminino nas quais exista nudez explicita como por exemplo o peito. Para editar o perfil e consequentemente as fotografias o utilizador terá que eliminar ou trocar essas fotografias por outras que tenha no seu telemóvel.

\section{Vestuário}

Relativamente ao vestuário foram encontradas, sem surpresas, diferenças de género, com as mulheres com roupas tidas como femininas (vestidos, por exemplo) e homens com roupa masculina. Esta dimensão de análise foi ainda desdobrada em dois polos opostos - formal versus informal. De acordo com este tipo de seriação dicotómica o tipo de vestimenta mais formal (fato completo e gravata, vestidos formais) foi menos encontrado, sendo interessante referir que a este tipo de formalidade estava muitas vezes associado determinados rituais $\mathrm{e}$ contextos cerimoniais à partida com cobertura fotográfica profissional - como por exemplo casamentos, batizados entre outras festividades.

Por seu turno a informalidade foi nota dominante, tendo sido possível encontrar sobretudo roupa mais informal e até algumas nas quais os utilizadores estão fantasiados.

\section{Estado de espírito}

Foi ainda pertinente tentar catalogar uma dimensão denominada de estado de espírito, manifestando-se este de forma mais ou menos latente através de expressões faciais com um ar introspetivo, pensativo, sorridente ou até divertido e corporais tais como, nomeadamente, sinais com as mãos. Foram sobretudo encontradas expressões como: sinal V, polegar para cima como sinal de gosto do Facebook, sinal da Hang Loose.

\section{Categoria profissional}

Interessante do ponto de vista a construção identitária, da análise da amostra emergiu igualmente a categoria ocupação profissional. Esta remetia para objetos fotográficos relacionadas com atividades profissionais ou em contexto laboral (com farda ou com máscara hospitalar, numa palestra). As referidas categorias têm uma determinada importância na medida em que é através desta apresentação visual e consequentemente do conteúdo imagético que o utilizador compõe a sua fachada pessoal de acordo com o papel que este está a representar. 
Em todas as dimensões até aqui analisadas não foram encontradas diferenças significativas no que ao género diz respeito.

\section{Contexto da fotografia}

Focando a análise no contexto da fotografia, do total da amostra analisada, $38,1 \%$ foram captadas em contexto indoor e $58,1 \%$ em contexto outdoor - o percentual remanescente $(3,8 \%)$ foi catalogado como impercetível nos casos de aferição categórica impossível.

\section{Temáticas da fotografia}

Dentro da grande categoria outdoor sobressaiu uma subcategoria que remetia para a temática de viagens/turismo dividindo-se em natureza, através da partilha de fotografias relacionadas com o ar livre, praia ou campo, e cidade, nas quais os utilizadores se encontravam num contexto citadino ou através da partilha de imagens onde constava de forma mais ou menos evidente algum tipo de património monumental e/ou arquitetónico minimamente reconhecível e popular - casos da Torre de Pisa ou Cristo Rei. A elevada partilha deste tipo de imagens parece então reconhecer e legitimar o valor que, de forma mais ou menos transversal, é atribuído a práticas turísticas, mobilidade e à esfera do lazer (Rojek, 2010). Refira-se que este tipo de fotografias foi maioritariamente empregue por utilizadores do género masculino.

Ainda no lazer, mas noutra dimensão, surgiu ainda uma categoria relacionada com as práticas culturais e atividades artísticas (coletivas e individuais). Podemos desdobrar esta classe de imagens em dois grandes posicionamentos face às práticas culturais retratadas - consumo versus produção. Por um lado, imagens de assistência a concertos de música ou num contexto museológico, e, por outro, fotografias que retratavam um envolvimento ativo numa dada produção cultural e artística - por exemplo, de utilizadores a tocar um instrumento ou a fotografar. Embora não existissem grandes diferenças de género no que ao consumo dizia respeito, foi na prática que o género masculino tendeu a estar sobre representado.

Outra categoria com expressão tinha ligações com o universo desportivo. De forma similar com o tratamento anterior esta foi divida entre assistência/apoio (através da partilha de fotografias num estádio) tendo sido ainda adicionado a subcategoria de clubismo (evidenciada através da partilha de fotografias com bandeira ou símbolos de clube) e prática desportiva efetiva.

Olhando para a prática desportiva a grande maioria de fotografias partilhadas remetiam para atividades tidas como radicais tais como o surf, o rappel, o snowboard, o mergulho, o paraquedismo ou desportos motorizados. No entanto, desportos como o golfe ou ténis, potencialmente consideradas mais elitistas, também estavam representados. As fotografias pertencentes a esta categoria eram partilhadas na sua maioria por utilizadores do género masculino (28 versus 10), verificando-se também uma maior frequência das mesmas nos seus perfis. Numa esfera imagética mais material surgiram fotografias de sujeitos em carros e em barcos, estando os mesmos a conduzir ou apenas a posar. Novamente eram os indivíduos do género masculino os que mais partilhavam este tipo de conteúdos sendo que os podiam indiciar a um determinado estatuto socioeconómico. Em contraste com esta maior masculinização (práticas culturais/desporto/motores), emergiu ainda uma última categoria relacionada com consumos latos e de bem-estar através da partilha de fotografias em locais com 
valências de spa, em estabelecimentos comerciais ou a ser maquilhada, sendo que foi quase exclusivamente $o$ género feminino que partilhou este conteúdo.

Por fim, com presença residual, entre as 701 fotografias apenas uma era eminentemente política e outra com celebridades.

\section{A componente escrita}

No momento da construção do perfil, o Tinder reserva um espaço de 500 caracteres para o utilizador partilhar um conjunto de informações que considere importantes sendo que dados como nome, idade, escola e trabalho são importados diretamente do Facebook. Da amostra, 50\% dos utilizadores partilharam informação referente à escola enquanto $28,5 \%$ partilhou informação referente ao trabalho, não se registando relações fortes entre este tipo de informação e o género.

\section{Informações sociodemográficas disponibilizadas por escrito}

Relativamente a aspetos sociodemográficos, metade indicou qual a instituição escolar que frequenta ou frequentou, dos quais $57 \%$ eram do género masculino e $43 \%$ do género feminino. Dos $28,5 \%$ que indicavam o "emprego", $54,4 \%$ eram do género feminino e $45,6 \% \%$ do género masculino. Finalmente, de entre a amostra $43,5 \%$ (87) dos utilizadores optou por partilhar informação extra sendo que aqui se encontraram diferenças de género: eram maioritariamente os utilizadores pertencentes ao género masculino $64,4 \%$ contra $34,5 \%$ do género feminino que utilizaram o espaço disponível para acrescentar informações escritas ao conteúdo fotográfico. O avanço de informação extra poderá ser justificado em parte com a teoria de Goffman (1993) e com o propósito de o utilizador compor a sua fachada pessoal sendo esta reforçada, e vice-versa, pelo desempenho (componente visual).

\section{Outro tipo de informações}

De entre os utilizadores que partilharam informação extra $(43,5 \%)$, a grande maioria $(83,9 \%)$ optou por partilhar conteúdo original, maioritariamente informações sobre si. Por seu turno apenas $16,1 \%$ partilharam conteúdo não original, tais como frases feitas, citações de terceiros ou letras de músicas. Tanto na partilha de informação extra como no recurso a conteúdo original é o género masculino que mais se destaca.

De entre as informações mais partilhadas destacaram-se aquelas que foram à posteriorienglobadas na categoria "estilo de vida" correspondendo a $42,5 \%$ dos utilizadores. Foram ainda $27,5 \%$ os que veicularam texto referente à "personalidade", $25,2 \%$ partilhou os seus "gostos pessoais", $24,1 \%$ indicou qual a sua postura na aplicação e 22,9\% revelou o que "espera do outro". É importante mencionar que apesar de ser uma prática mais masculinizada, em nenhum momento se registaram diferenças em função do género no que diz respeito ao tipo de informação partilhada. Através da Figura 4 com o top 5 de informação mais partilhada, percebe-se a importância do estilo de vida, com quase metade dos textos a veicularem informações nesse sentido. 
Figura 4: 5 tipos de informações mais partilhadas de forma escrita $-n=87$

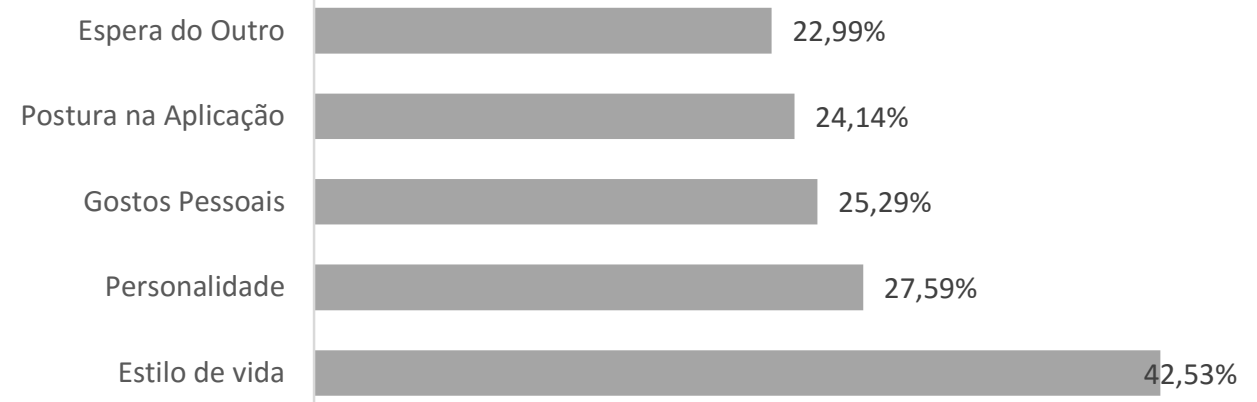

\section{Uso de emojis}

No que toca a recursos expressivos por escrito, para além dos utilizadores terem revelado sobre si informação ou características que consideravam importantes, $22,9 \%$ fazia-o com o recurso a emojis, elementos que podem ser definidos como "ícone emocional, ou expressão pictórica das emoções vividas no momento" (Silva, 2002: 9)

Analisando de forma isolada estes perfis, o emprego destes símbolos serviu, em parte, para complementar a informação disponibilizada, acrescentar dados à mesma ou ilustrar situações ou emoções. Tal uso vai de encontro ao tipo de motivação elencadas pela teoria, nomeadamente a tentativa de entoação emocional à mensagem que se pretende (Baptista, 2015). O uso de recursos expressivos para além de letras (Baym, 2011) poderá auxiliar o grau de riqueza simbólica da comunicação mediada e podem de alguma forma influenciar a interpretação da mensagem na medida em que "pistas não verbais geralmente influenciam a interpretação da mensagem e a perceção do indivíduo" (Ganster, 2014: 229). Estes podem alterar o tom e, como tal, também os formatos de interpretação - quer seja em ambiente mediado ou não (Fullwood, 2012: 649) logrando, portanto, serem considerados como uma mais valia no momento de comunicar online.

Como corroboraram os entrevistados que consideraram que estes símbolos ajudavam de alguma forma na autoapresentação, afirmando um deles "pode ser simpático ter um smile para dar algum mood à frase" (Anónimo 5, 32 anos) e outro "podem transmitir mensagens que as palavras não são capazes" (Anónimo 8, 32 anos).

\section{Comunicação mediada extra Tinder}

Como referido inicialmente, a possibilidade de comunicação mediada pela plataforma só acontece após combinação mútua entre os perfis - sem essa condição não é possível estabelecer uma conversação direta. Contudo, talvez até como forma de transposição desse constrangimento estrutural tecnológico imposto pela plataforma Hogan (2010), daqueles que partilhavam informação extra, 5,7\% fornecia outro tipo de contacto neste caso outra rede social online - Facebook foi a mais recorrente.

Sinónimo não só da convergência e sinergias entre plataformas, mas também da disponibilização de mais pistas sobre o eu, $9 \%$ dispunha ligação para uma conta Instagram e 
3,5\% Spotify. Estas duas talvez mais como forma de desvelamento das culturas visuais e musicais pessoais e como tal na procura de distinções de gosto potenciais afinidades eletivas (Bourdieu, 2010: 362-67) do que como potenciais plataformas conversacionais.

\section{Línguas utilizadas}

No que toca à língua utilizada denotou-se que dos sujeitos da amostra que fornecia informação extra mais de metade (58\%) optou por as redigir conjuntamente em inglês, traduzindo o idioma nacional. A tal escolha não será alheia à tendência para uma crescente mobilidade global e a capacidade de atração turística da cidade de Lisboa aliada ao facto do Tinder ser uma rede global onde não estão registados apenas utilizadores de nacionalidade portuguesa. Desta forma a proliferação linguística do inglês aumentará o grau de alcance e, como tal, a probabilidade de correspondência com mais utilizadores. De resto tal perceção é resgatada nas entrevistas em que o inglês foi encarado como uma língua franca, "mais universal" (Anónimo 4, 34 anos) e que demonstra uma disponibilidade e procura cosmopolita - "mostram que estão disponíveis para conhecer portuguesas e estrangeiras, ou seja, vale tudo" (Anónimo 6, 35 anos).

\section{Estado civil}

Por fim, no que toca a indicações sobre o estado civil, denotou-se que esta prática foi claramente residual. Apenas um utilizador, do género masculino, o fez, indicando que era casado. Isolando o seu perfil, este continha somente uma fotografia sendo a mesma de conteúdo não identificável. Este dado parece revelar alguma consciencialização da fragilidade da privacidade nesta rede e, como tal, alguma prudência comunicativa na medida em que parece consciente da potencial identificação de terceiros registados na mesma aplicação.

\section{Palavras mais utilizadas}

Passando a uma abordagem quantitativa analisaram-se as 10 palavras utlizadas com mais frequência (excetuando pronomes e determinantes recorrentes) por ambos géneros representado na Figura 5 .

As mesmas remetiam para dados da biografia pessoal como por exemplo a nacionalidade, assim como a partilha de elementos relativos ao estilo de vida ou dos seus gostos pessoais. Por outro lado, também se verificou uma consciencialização por parte do utilizador relativamente ao propósito da rede indicando quais os seus objetivos na mesma através de palavras como "pessoas", "novas" ou "looking".

Figura 5: Top 10 palavras mais utilizadas

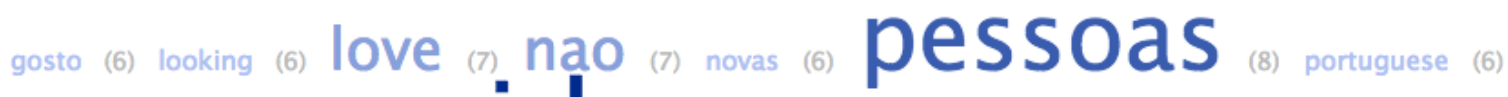 sou $_{\circledast}$ travel $_{\circledast}$ vida $_{\circledast}$}


Desdobrando este olhar por género verificámos que as palavras a que o género masculino - Figura 6 - recorreu denotavam a importância do contexto da aplicação "aqui", bem como uma partilha do tipo de atividades que gostava de realizar "cinema", a importância de outros "amigos" e o que estava à procura na rede "procuro", "pessoas" e "love".

Figura 6: Top 10 palavras mais utilizadas pelo género masculino

\section{amigos \\ pessOas}

Já a subamostra do género feminino, tal como se pode verificar na Figura 7, procurou apresentar-se através da utilização do vocábulo "sou" e da partilha de dados biográficos "portuguese". Verificou-se a existência de noção do registo na rede "estou" à qual se sucedia a indicação daquilo que procurava "looking" e "someone" e do que pretendia evitar "não".

Figura 7: Top 10 palavras mais utilizadas pelo género feminino

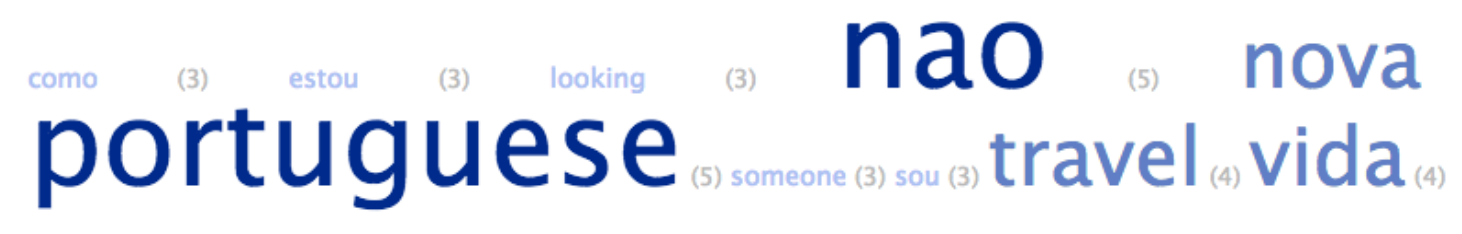

Através desta análise afirmasse que a componente escrita da autoapresentação é sobretudo composta por três elementos: aquele no qual o utilizador se apresenta, aquele em que partilha os seus gostos pessoas e por fim quais os objetivos do seu registo da rede através da indicação do que procura e que vai de certa forma ao encontro dos dados encontrados na análise do tipo de informação partilhada.

\section{Considerações finais}

Triangulando os resultados obtidos através da informação facultada pelos dados secundários, com a informação revelada pelos utilizadores aquando da realização das entrevistas e dados resultantes da observação produziram-se evidências e conhecimento sobre as formas de apresentação dos portugueses nas redes sociais de online dating em Portugal.

O perfil do utilizador português do Tinder nesta amostra caracterizou-se por conter em média quatro fotografias, a cores, nas quais se encontra maioritariamente identificável e no que diz respeito à composição, o primeiro plano foi o mais comum. Não será, no entanto, de menosprezar o peso da criação de identidades anónimas nesta rede específica.

Apesar da rede em estudo se tratar de uma plataforma de encontros e namoro online, e como tal poder existir uma expectativa relativamente à natureza das fotografias e exposição do corpo, apenas $9,8 \%$ dos utilizadores da amostra exibe o corpo e, mesmo assim, essa exibição foi comedida e muitas vezes consequência do próprio 
contexto da fotografia (na praia ou na piscina). É importante ter em conta as affordances da própria rede e como é que o perfil é construído e qual a imagem e mensagem que os utilizadores desejam transmitir, recordese os resultados dos estudos de Miguel (2016) onde utilizadores com fotografias sexy eram descartados. Recordemos também os contributos de Mead $(1934 ; 1972)$ e de Goffman $(1983,1993)$ no que à autoapresentação do eu diz respeito e os conceitos de fachada pessoal e desempenho através dos quais conseguimos compreender a importância da escolha da informação escrita e visual que os utilizadores partilham. Afirmamos que se denota uma possível consciencialização prática do utilizador do conceito audiência imaginada (Litt, 2012; Vitak, 2012) e do conceito colapso dos contextos (boyd, 2014). Tal perceção pode assim condicionar a autoapresentação online. Ainda que se verifiquem algumas diferenças, a relativa homogeneização da amostra no tipo de fotos partilhadas poderá estar de alguma forma relacionada com a arquitetura da rede, nomeadamente o facto de esta importar diretamente conteúdo do Facebook, rede generalista e onde segundo o estudo Sociedade em Rede (2014) $98 \%$ dos portugueses utilizadores de redes sociais online (78,3\% dos utilizadores de internet) tem conta. Segundo dados de 2015 da Entidade Reguladora da Comunicação (2016) $79,9 \%$ dos utilizadores de internet afirmava utilizar redes sociais online. Dada a crescente popularização do uso de redes sociais online é expectável que nessa conhecida rede estejam presentes outros grupos sociais como familiares, amigos, colegas, entre outros e que em função destes e da audiência imaginada as fotografias que compõem o perfil dos utilizadores não fossem as mesmas que as partilhadas em redes de online dating. Ainda que o utilizador tenha oportunidade de editar o perfil e trocar fotografias por outras mais intimas, prefere não o fazer ou não tem literacias para tal.

Dentro da dispersão e diversidade de um corpus empírico com 701 imagens, emergiram alguns padrões temáticos nomeadamente no que ao contexto fotográfico diz respeito, particularmente no que toca ao vestuário e acessórios (mais masculinos ou femininos), mas também práticas associadas a universos como as viagens/turismo e consumo e práticas culturais ou desportivas, e que parecem legitimar a importância das mesmas na construção da autoapresentação e da sua valorização em processos identitários. Apesar de se registar em fotografias pontuais a emergência da categoria profissional, a informalidade é uma tónica comum nas fotografias partilhadas, mais uma vez possivelmente justificada pela própria natureza da plataforma bem como pela importância do conteúdo imagético na construção da fachada pessoal (Goffman, 1993).

Respeitante a eventuais diferenças ventiladas pelo género dos analisados não foram encontradas diferenças expressivas, excetuando somente em algumas sub-temáticas específicas. De forma residual foram partilhadas algumas fotografias dentro da temática material assim como fotografias pertencentes à esfera do bem-estar, $\mathrm{e}$ nestes contextos registadas diferenças de género. $\mathrm{Na}$ esfera das representações de práticas consideradas mais masculinizadas é o género masculino que mais partilha fotografias pertencentes à temática material nomeadamente fotografias com carros, relógios, em barcos, mas também práticas de lazer e turismo, bem como assistência e consumos de atividades culturais ou prática desportiva efetiva - sobretudo desportos radicais. Embora de forma muito residual, foram encontradas 4 fotografias de mulheres com cuidados do corpo, tratamentos de beleza ou por exemplo em contexto de spa. No entanto, não foram partilhadas representações de homem em práticas de cuidados com o corpo. Estes dados parecem ir de encontro a outros estudos, representações e estereótipos de género em que "ao vender a si mesmo, os homens publicitam os seus recursos financeiros e ocupação, enquanto mulheres oferecem atratividade física e forma do corpo atraente" (Jagger, 2001: 39). Note-se ainda que as escolhas individuais para a apresentação do eu tendem a reproduzir (e legitimar) a cultura global dominante e as lógicas visuais e estereótipos dos media institucionais. 
Passando à informação no plano textual partilhada de forma automática por omissão, os utilizadores portugueses preferem revelar a escola que frequentam ou frequentaram em detrimento do seu trabalho (50\% versus 28,5\%), no entanto é importante voltar a referir novamente as affordances da própria rede e em que medida as mesmas podem condicionar a partilha de informação já que esta esta informação específica apenas podia ser editada no Facebook e não diretamente no Tinder. Curiosamente estes não são aspetos que pareciam incomodar os utilizadores nem a sua relação com a plataforma. Quando inquiridos sobre o que consideravam mais frustrante na aplicação foi referido o facto de esta não ter um campo de pesquisa por nome "Não ser possível pesquisar pelo nome" (Anónimo, 32 anos) ou não existir pesquisa por interesses "Não conseguir afunilar melhor os resultados ao não se ter possibilidade de escolher características daqueles que se procuram" (Anónimo, 36 anos). Esta informação remete-nos para os contributos de Hogan (2010) e o seu conceito de "curador" em que o utilizador é o seu próprio algoritmo.

Relativamente à informação avançada propositada e conscientemente, denota-se alguma inibição discursiva, sendo que menos de metade (43,5\%) partilharam informação extra. Ainda assim, e entre aqueles que fazem questão de partilhar informações extra, estas, após análise, recaem em três grandes temáticas: informações sobre si mesmo, aspetos relacionados com o estilo de vida e o que espera do outro. Olhando para questões de género, foram mais os homens a revelar informações extra - 64,4\% escreveram versus 34,5\% das mulheres. O utilizador parece estar consciencializado da possível ausência de entoação ou emoção na informação que pretende transmitir, aspeto comum à comunicação mediada e assíncrona como referido por Baym (2011) e Gunter (2014), e tal como aponta Baptista (2015) como forma de mitigá-la recorre a emojis, quer homens, quer mulheres.

Rematando, apesar da análise ter procurado práticas diferenciadas de apresentações e fluxos comunicacionais e simbólicos consoante o género, não foi possível afirmar que essa variável fosse explicativa por não terem sido encontradas grandes variações para além de mais representações de atividades e de um maior número de homens a partilharem informação textual.

Como oportunidades e pistas para agendas de investigação futura apela-se à monitorização longitudinal da tendência - será que esta continuará no tempo?, mas também ao alargamento da amostra. Seria igualmente interessante mobilizar um método comparativo, confrontando diferentes redes, com diferentes culturas, comunidades, e, no plano tecnológico, affordances.

É possível afirmar que as diferentes estratégias de apresentação para o outro consoante os contextos (mais ou menos colapsados), demonstram reflexividade por parte dos sujeitos num interessante jogo dialético de expectativas recíprocas e leitura dos contextos mediados. Encontraram-se fortes regularidades sociais, o que demonstra o carácter situacional da apresentação do eu que molda as lógicas de ação. Ou seja, foi desvelada a "ordem da interação" (Goffman, 1983) num contexto mediado de apresentação pública cada vez mais em rede e colapsado que integra vários contextos sociais num só - e em que as fronteiras com o privado (bastidores) cada vez mais esboroadas. 


\section{Referências}

Almeida, Miguel (1995) Senhores de si: uma interpretação antropológica da masculinidade, Celta, Oeiras

Amâncio, Lígia Queiroz (1994), Masculino e Feminino - A Construção Social da Diferença, Porto, Edições Afrontamento

Anderson, T., Emmers-Sommer, T., (2006), "Predictors of Relationship Satisfaction" em Online Romantic Relationships, Communication Studies, 57, 2, 53-175

Bakardjieva, Maria (2005) Internet society: The Internet in everyday life, Londres, Sage.

Banks, Marcus (2001) Visual Methods in Social Research. Londres: Sage

Baptista, T. (2015), "Infidelidade digital: Uma Velha História com Novos Meios", em Guilhermina Lobato Miranda (org.) Psicologia dos Comportamentos Online, Lisboa, Relógio D'Água

Bareket-Bojmel, L., Moran, S., Shahar, G., (2016), "Strategic self-presentation on Facebook: Personal motives and audience response to online behavior", Computers in Human Behavior, 55, pp. 788-795.

Bargh, J. A., Mcknenna, K. Y. A., Fitzsimons, G. M. (2002), "Can You See the Real Me? Activation and Expression of the "True Self" on the Internet", Journal of Social Issues, Volume 58, Issue 1, pp. 33-48.

Baumgartner, S. E., Sumter, S. R., Peter, J., Valkenburg, P. M., (2015), "Sexual self-presentation on social network sites: Who does it and how is it perceived?", Computers in Human Behavior, 50, 91-100.

Baym, Nancy (2011) Personal Connections in the Digital Age, Polity Press

Bell, Philip (2008) 'Content analysis of visual images', in van Leeuwen, Theo \& Carey Jewitt (2008) Handbook of Visual Analysis, pp. 10-34, Londres, Sage

Berker, Thomas el al.. (2006) Domestication of Media and Technology, Berkshire, Open University Press.

Bilton, N., (2014) Tinder, the Fast-Growing Dating App, Taps an Age-Old Truth, 6 Março 2016. Disponível em http://www.nytimes.com/2014/10/30/fashion/tinder-the-fast-growing-dating-app-taps-an-age-oldtruth.html

Blackwell, C., Birnhltz, J., Abbott, C., (2014), "Seeing and being seen: Co-situation and impression formation using Grindr, a location-aware gay dating app", New Media \& Society.

Blaikie, Norman W H (2000) Designing Social Research, Cambridge, Polity.

Bourdieu, Pierre (2010) A distinção. Uma crítica social da faculdade do juízo, Lisboa, Edições 70

Bourdieu, Pierre (2013) A Dominação Masculina, Lisboa, Relógio de Água

Boyd, d., (2010), "Social Network Sites as Networked Publics: Affordances, Dynamics, and Implications" Em Zizi Papacharissi, Networked Self: Identity, Community, and Culture on Social Netwok Sites, 39-58

Boyd, d., (2014) It's Complicated: The Social Lives of Networked Teens, Yale University Press

Bryman, A., (2012), Social Research Methods, Oxford, Oxford University Press

Butler, J. (1988) 'Performative acts and gender constitution: An essay in phenomenology and feminist theory', Theatre journal 40(4), 519-531

Cardoso, G. (2014), A Internet em Portugal - Sociedade em Rede 2014. Obercom

Cash, T. el al. (2004) "Body image in an interpersonal context: Adult attachment, Fear of Intimacy, and Social Anxiety", Journal of Social \& Clinical Psychology, 23(1), 89-103

Casimiro, Cláudia (2015) 'Self-presentation in the Portuguese Online Dating Scene: Does Gender Matter?', in Degim, I Alev el al.. (eds) (2015) Online Courtship - Interpersonal Interactions Across Borders, pp. 7195, Amsterdam, Institute of Network Cultures. 
Chambers, Deborah (2013) Social Media and Personal Relationships - Online Intimacies and Networked Friendship, Hampshiee, Palgrave Macmillan.

Chappetta, K., Barth, J. (2016) How gender role stereotypes affect attraction in an online dating scenario, Computers in Human Behavior, 63, 738-746

Chiang, J. K., Suen, H. (2015), "Self-presentation and hiring recommendations in online communities: Lessons from LinkedIn", Computers in Human Behavior, 48, 516-524.

Connel, R W (2005a- 2a edição) Masculinities, Berkerley, University of California Press

Connell, R W (2005b) 'Hegemonic Masculinity: Rethinking the Concept', Gender \& Society 19(6),

Cooley, Skye C \& Lauren Reichart Smith (2013) 'Presenting me! An examination of self-presentation in US and Russian online social networks', Russian Journal of Communication 5(2), 176-190.

Couldry, Nick (2012) Media, Society, World: Social Theory and Digital Media Practice, Polity Press

Creswell, John W (2014) Research design: Qualitative, quantitative, and mixed methods approaches. Londres, Sage.

De Vries, J. (2010) Impact of Self- Description and Photographs on Mediated Dating Interest, Marriage \& Family Review, 46:8, 538-562

De Vries, J., Swenson, L., Walsh, R. (2007) Hot Picture or great self-description: Predicting mediated dating success with parental investment theory. Marriage and Family Review, 42(3), 7-34

DeMasi, S. (2006) "Shopping for love: Online dating and the making of a Cyberculture of Romance", in Seildman, S., Fischer, N., Meeks, C. (eds.), Handbook of the New Sexuality Studies, Routledge International Handbooks, Londres, 223-232

Dutton, W. H., Helsper, E., Whitty, M. T., Nai, L., Buckwalter, J. G., and Lee, E. (2009). "The Role of the Internet in Reconfiguring Marriages: A Cross-National Study," Interpersona, 3 (2), 3-18.

Dutton, W., (2013), "The Study of Online Relationships and Dating" em The Oxford Handbook of Internet Studies, Oxford Handbooks Online

Ellison, N. B., Heino, R. Gibbs, J. L., (2006), "Managing Impressions Online: Self-Presentation Processes in the Online Dating Environment", Journal of Computer-Mediated Communication, 11, 415 - 441

Entidade Reguladora da Comunicação (2016) As novas dinâmicas do consumo audiovisual em portugal, Lisboa, ERC.

Eysenbach, G. e Till, J. (2001) Ethical issues in qualitative research on internet communities, BMJ, 323, 11031105

Finkel, E., et. al (2012), " Online Dating: A Critical Analysis From the Perspective of Psychological Science", Psychological Science in the Public Interest, 13, 3-66

Fischer, Claude S. (1993) America Calling: A Social History of the Telephone to 1940, Berkeley, University of California Press

Fuchs, Christian (2014) Social Media. A critical introduction. Londres, Sage

Fullwood, C., Orchard, L., Floyd, S. (2012). "Emoticon convergence in Internet chat rooms", Social Semiotics, 23, 648-662

Ganster, T., Eimler, S.C., Krämer, N., (2012), "Same Same But Different? The Differential Influence of Smilies and Emoticons on Person Perception", Cyberpsychology, Behavior, and Social Networking, 15(4), 226230

Gershon, I. (2010), The Breakup 2.0 - Disconnect over New Media, Cornell University Press.

Gibbs, J. L., Ellison, N. B., Heino, R. D., (2006) "Self-Presentation in Online Personals - The Role of Anticipated 
Future Interaction, Self-Disclosure, and Perceived Success in Internet Dating" Communications Research, Sage Publications, V 33 (2), 152-177.

Gillespie, T. (2015), "Platforms Intervene", Social Media + Society

Goffman, Erving (1983), "The interaction order", American Sociological Review, 48 (1), pp. 1-17

Goffman, Erving (1993), A Apresentação do Eu na Vida de Todos os Dias, Lisboa, Relógio D’Água.

Granovetter, Mark S. (1983) "The Strength of Weak Ties: A Network Theory Revisited." Sociological Theory, 1, 201-233.

Granovetter, Mark S. (1973) "The Strength of Weak Ties." The American Journal of Sociology, 78 (6), 13601380.

Guadagno, R., Okdie, B., Kruse, S. (2012), "Dating deception: Gender, online dating, and exaggerated selfpresentation", Computers in Human Behavior, 22, 642-64

Gunter, B. (2008) Internet Dating: A British Survey, Aslib Proceedings, 60(2): 88-97.

Haddon, Leslie (2004) Information and communication technologies in everyday life: $A$ concise introduction and research guide, Oxford, Berg.

Hall, J. A., Park, N., Song, H., Cody, M. J., (2010), "Strategic misrepresentation in online dating: The effects of gender, self-monitoring, and personality traits", Journal of Social and Personal Relationships.

Hardey, Michael. (2002), "Life beyond the screen: embodiment and identity through the internet." Editorial Board of The Sociological Review. pp. 570-585.

Haythornthwaite, C. (2002) Strong, weak, and latent ties and the impact of new media. The Information Society, 18, 1-17.

Hinton, Sam e Hjorth, Larissa (2013) Understanding Social Media, Londres, Sage

Hjorth, Larissa \& Sun Sun Lim (2012) 'Mobile intimacy in an age of affective mobile media', Feminist Media Studies 12(4), 477-484.

Hogan, B. (2010), "The Presentation of Self in the Age of Social Media: Distinguishing Performances and Exhibitions Online", Bulletin of Science, Technology \& Society, 30, 377-386

Holmes, M. (2007) What is gender? Sociological Approaches, Sage Publications

Hooley, Tristram el al.. (2012) What is Online Research? Using the Internet for Social Science Research, Londres, Bloomsbury.

Humphreys, Lee (2006) 'Photographs and the Presentation of Self through Online Dating Services', in Paul Messaris and Lee Humphreys (eds) Digital Media: Transformations in Human Communication, New York: Peter Lang, pp. 39-49.

Hutchby, Ian (2001) Technologies, texts, and affordances, Sociology, 35(2), 441-456.

INE (2016) Sociedade da Informação e do Conhecimento - Inquérito à Utilização de Tecnologias da Informação e da Comunicação nas Famílias, INE, disponível em www.ine.pt

Jagger, E., (2001), "Marketing Molly and Melville: Dating in a Postmodern, Consumer Society". Sociology. 35 (1), 39-57

Jamieson, Lynn (2013) Personal Relationships, Intimacy and the Self in a Mediated and Global Digital Age in Orton-Johnson, Kate \& Nick Prior (eds) (2013) Digital Sociology. Critical Perspectives, Palgrave Macmillan.

Jensen, Klaus Bruhn (2012 - 2a edição) A Handbook of Media and Communication Research: Qualitative and Quantitative Methodologies, Londres \& New York, Routledge. 
Kang, T., Hoffman, L., (2011), "Why Would You Decide to Use an Online Dating Site? Factors That Lead to Online Dating", Communication Research Reports, 28, 3

Lawson, H. M., Leck, K., (2006), "Dynamics of Internet Dating", Social Science Computer Review 24, pp. 189208.

Lee-won, R. J., Shim, M., Joo, Y. K., Park, S. G., (2014), "Who puts the best "face" forward on Facebook?: Positive self-presentation in online social networking and the role of self-consciousness, actual-to-total Friends ratio, and culture", Computers in Human Behavior, 39, 413-423.

Lenhart, A. (2009), "Teens and Sexting" 18 Janeiro 2017. Disponível em http://www.pewinternet.orq/2009/12/15/teens-and-sexting/

Licoppe, C., Riviére, C.A., Morel, J. (2015) "Grindr casual hook-ups as interactional achievements", New Media \& Society, 1-19

Lievrouw, L. (2012) "The Next Decade in Internet Time, Information, Communication \& Society", 15:5, 616-638 Lievrouw, Leah A \& Sonia Livingstone (2006) 'Introduction to the updated student edition', em Lievrouw, Leah A \& Sonia Livingstone (2006) Handbook of New Media. Social Shaping and Consequences of ICTs, Londres, Sage.

Lips, Hilary. (2013) Gender: The basics. New York: Routledge.

Litt, E. (2012) "Knock, knock. Who's There? The imagined audience", Journal of Broadcast \& Electronic Media, $56,330-345$

Litt, E., Hargittai, E., (2016), "The Imagined Audience on Social Network Sites", Social Media + Society

Livingstone, Sonia (2004) The Challenge of Changing Audiences Or, What is the Audience Researcher to do in the Age of the Internet? European Journal of Communication, 19(1), 75-86

Madden, M., Lenhart, A., (2006), "Online dating", 11 Fevereiro 2016. Disponível em http://www.pewinternet.org/2006/03/05/online-dating/

Marvin, Carolyn (1998) When Old Technologies Were New: Thinking About Electric Communication in the Late Nineteenth Century, Nova Iorque, Oxford University Press

McGrath, F., (2015), What to know About Tinder in 5 Charts, 20 Fevereiro 2016. Disponível em www.globalwebindex.net/blog/what-to-know-about-tinder-in-5-charts

McKenna, K. Y. A., Green, A. S., Gleason, E. J., (2002), "Relationship formation on the Internet: What's the big attraction?", Journal of Social Issues, 58, 9-31.

Mead, G.H. (1934) "Mind, Self, and Society", Charles W. Morris (eds) University of Chicago Press, Chicago

Mead, George Herbert (1972) Mind, Self, and Society from the Standpoint of a Social Behaviorist, Chicago, University of Chicago Press.

Meyrowitz, J. (1985) No Sense of Place: The Impact of Electronic Media on Social Behavior, Oxford University Press

Miguel, C. (2016) "Visual Intimacy on Social Media: From Selfies to the Co-construction of Intimacies through Shared Pictures", Social Media + Society, SAGE, 1-10

Neves, Barbara Barbosa (2013) 'Social Capital and Internet Use: The Irrelevant, the Bad, and the Good', Sociology Compass 7(8), 599-611.

Pascoe, C.J. (2010) 'Intimacy', in Ito, M., Baumer, S., Bittanti, M., boyd, d., Cody, R., Herr-Stephenson, B., Horst, H.A., Lange, P.G., Mahendran, D., Martinez, K.Z., Pascoe, C.J., Perkel, D., Robinson, L., Sims, C., and Tripp, L. (eds.), Hanging Out, Messing Around, and Geeking Out: Kids Living and Learning with New Media. Cambridge, MA: MIT Press, pp. 117-148. 
Patra, S. (2015) "Online Participation and Self-presentation in Social Networking Sites: A Study of Selective Users of India", Journal of Creative Communication, 10(1)

Pereira, Maria do Mar (2012), Fazendo Género no Recreio: uma Etnografia da Negociação do Género na Escola, Lisboa: Imprensa de Ciências Sociais.

Rainie, Lee \& Barry Wellman (2012) Networked. The New Social Operating System, Cambridge, MIT Press.

Rettberg J.W. (2014) Written, Visual and Quantitative Self-Representations. In: Seeing Ourselves

Through Technology: How We Use Selfies, Blogs and Wearable Devices to See and Shape

Ourselves. Palgrave Macmillan, Londres.

Rojek, Chris (2010) The Labour of Leisure: The Culture of Free Time, Londres, Sage.

Rose, Gillian (2001). Visual Methodologies: An Introduction to the Interpretation of Visual Materials. Londres: Sage

Rui, J., Stefanone, M., (2013), "Strategic self-presentation online: A cross-cultural study", Computers in Human Behavior, 29, 110-118

Saldaña, Johnny (2009) The Coding Manual for Qualitative Researchers, Londres, SAGE.

Salmons, Janet E (2016) Doing Qualitative Research Online, Londres, Sage.

Sandstrom, Kent L. ; Daniel D. Martin \& Gary Alan Fine (2001) Symbolic Interactionism at the End of the Century in Ritzer, George \& Barry Smart (2001) Handbook of social theory, New York, Sage.

Selwyn, N. (2012) "Making Sense of young people, education and digital technology: the role of sociological theory", Oxford Review of Education, 38(1), 81-96

Sevcikova, A., Daneback, K. (2011), "Anyone who wants sex? Seeking sex partners on erotic contact websites", Sex and Relationship Therapy, 26, 2

Siibak, A. (2009) Constructing the Self through the Photo selection - Visual Impression Management on Social Networking Websites. Cyberpsychology: Journal of Psychosocial Research in Cyberspace, 3(1)

Silfverberg S., Liikkanen A., Lampinen, A. (2011) "I'll press play, but I won't listen: profile work in a musicfocused social network servisse" em Proceedings of the ACM conference on computer supported cooperative work, Hangzhou, China, 19-23 March. New York, ACM Press

Silva, C., Sebastião, P., (2002) "Interacção \& Cibersexo no IRC" em Interacção e Ciberespaço - Sociologia em Diálogo, Universidade de Évora, Departamento de Sociologia, 23-49

Silverstone, Roger (1999) Why study the media?, Londres, Sage.

Silverstone, Roger (2005) 'The Sociology of Mediation and Communication', em Calhoun, Craig el al.. (orgs.) The Sage Handbook of Sociology, Londres, Sage.

Smith, A. (2016), 15\% of American Adults Have Used Online Dating Sites or Mobile Dating Apps, 11 Fevereiro 2016. Disponível em: http://www.pewinternet.org/2016/02/11/15-percent-of-american-adults-haveused-online-dating-sites-or-mobile-dating-apps/, consultado em 20 Fevereiro 2016

Solomon, Denise \& Jennifer Theiss (2012) Interpersonal Communication. Putting Theory into Practice, New York, Routledge.

Sprecher,S., (2009), "Relationship Initiation and Formation on the Internet", Marriage \& Family Review, 45, 68

Standage, Tom (2007) The Victorian Internet: The Remarkable Story of the Telegraph and the Nineteenth Century's On-line Pioneers, Nova Iorque, Berkley

Toma, C., Hancock, J. (2012) "What lies beneath: The linguistic traces of deception in online dating profiles", Journal of Communication, 62,78-97 
Uski, S., Lampinen, A., (2016), "Social norms and self-presentation on social network sites: Profile work in action", New media \& society, SAGE, 18(3) 447-464

Vernon, R., Sutherland, C., Young, A., Harley, T., (2014), "Modeling first impressions from highly variable facial images". PNAS, 111, 3353-3361

Vitak, J. (2012) "The impact of context collapse and privacy on social network site disclosures". Journal of Broadcasting \& Electronic Media, 56, 451-470.

Wajcman, Judy (2002) "Addressing Technological Change: The Challenge to Social Theory", Current Sociology 50(3), 347-363

Walther, J. B., (2007), "Selective Self-presentation in Computer-mediated Communication: Hyperpersonal Dimensions of Technology, Language, and Cognition", Computers in Human Behavior 23(5), 25382557.

Wesch, Michael (2009) 'Youtube and you: Experiences of self-awareness in the context collapse of the recording webcam', Explorations in Media Ecology 8(2), 19-34.

Whitty, M. T. (2008), "Revealing the 'real' me, searching for the 'actual' you: Presentations of self on an internet dating site". Computers in Human Behavior, 24, 1707-1723.

Wohlgemuth, J. (2005) "Vídeo Educativo: uma pedagogia audiovisual", Brasília, Senac - DF.

Wotipka, C. D., High, A. C., (2016), "An idealized self or the real me? Predicting attraction to online dating profiles using selective self-presentation and warranting", Journal Communication Monographs, 83, issue $3,281-302$.

Zytko, D., Grandhi, S. A., Jones, Q., (2014), "Impression Management Struggles in Online Dating" in Proceedings of the $18^{\text {th }}$ international conference on supporting group work, $53-62$. 